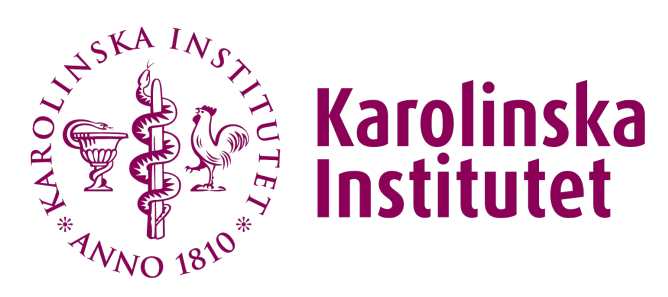

Karolinska Institutet

http://openarchive.ki.se

This is a Peer Reviewed Accepted version of the following article, accepted for publication in Journal of chromatography A.

\title{
Benzo[a]pyrene-specific online
}

\section{high-performance liquid}

chromatography fractionation of air

particulate extracts : a tool for

evaluating biological interactions

Lim, Hwanmi; Bergvall, Christoffer; Jarvis, Ian W H; Mattsson, Åse; Dreij, Kristian; Stenius, Ulla; Westerholm, Roger

\footnotetext{
J Chromatogr A. 2014 Aug 15;1355:100-6.

Elsevier

http://doi.org/10.1016/j.chroma.2014.05.082

http://hdl.handle.net/10616/45985
}

If not otherwise stated by the Publisher's Terms and conditions, the manuscript is deposited under the terms of the Creative Commons Attribution-NonCommercial-NoDerivatives License (http://creativecommons.org/licenses/by-nc-nd/4.0/), which permits non-commercial re-use, distribution, and reproduction in any medium, provided the original work is properly cited, and is not altered, transformed, or built upon in any way. 


\section{(19) \\ Karolinska Institutet}

This is the peer reviewed version of the following article J Chromatogr A. 2014 Aug 15;1355:100-6. which has been published in final form at:

http://dx.doi.org/10.1016/j.chroma.2014.05.082

Benzo[a]pyrene-specific online high-performance liquid chromatography fractionation of air particulate extracts : a tool for evaluating biological interactions.

Lim, H; Bergvall, Christoffer; Jarvis, Ian WH; Mattsson, $\AA$; Dreij, Kristian; Stenius, Ulla; Westerholm, Roger

Access to the published version may require subscription. Published with permission from: Elsevier 
1 Benzo[a]pyrene-specific online HPLC fractionation of air particulate extracts - A tool for

2 evaluating biological interactions

3 Hwanmi Lim $^{\mathrm{a}}$, Christoffer Bergvall ${ }^{\mathrm{a}}$, Ian Jarvis ${ }^{\mathrm{b}}$, Åse Mattsson ${ }^{\mathrm{b}}$, Kristian Dreij ${ }^{\mathrm{b}}$, Ulla Stenius ${ }^{\mathrm{b}}$, Roger Westerholm ${ }^{\mathrm{a}, *}$

$4{ }^{a}$ Department of Analytical Chemistry, Stockholm University, Svante Arrhenius väg 16 SE-106 91 Stockholm,

5 Sweden

$6 \quad{ }^{\mathrm{b}}$ Institute of Environmental Medicine, Karonlinska Institutet, Box 210, SE-171 77 Stockholm, Sweden

7 * Corresponding author: Department of Analytical Chemistry, Stockholm University, Svante Arrhenius väg 16 SE-

810691 Stockholm, Sweden. E-mail: roger.westerholm@anchem.su.se. Tel: +46-8-16 24 40. Fax: +46-8-15 6391.

10 ABSTRACT

11 Benzo[a]pyrene $(\mathrm{B}[a] \mathrm{P})$ is a known human carcinogen and is commonly used as a surrogate for assessing the 12 carcinogenic risk posed by complex mixtures of polycyclic aromatic hydrocarbons (PAHs) present in air particulate 13 matter $(\mathrm{PM})$. However, studies have shown that using $\mathrm{B}[a] \mathrm{P}$ as a surrogate may underestimate the carcinogenic 14 potential of PAH mixtures, as the risk assessment approach does not consider interaction effects. Thus, toxicological 15 studies using $\mathrm{B}[a] \mathrm{P}$ to assess its carcinogenic potential in environmentally derived complex mixtures, as opposed to 16 single compound experiments, could improve risk assessment. The intention of the present study was to develop an 17 online HPLC fractionation system for the selective removal of $\mathrm{B}[a] \mathrm{P}$ from air PM extracts. Two serial pyrenylethyl 18 (PYE) columns enabled selective separation of $\mathrm{B}[a] \mathrm{P}$ from its isomers and other PAHs as well as a short 19 fractionation cycle of 30 minutes. One run consisted of three collection steps: the first fraction contained PAHs 20 eluting earlier than $\mathrm{B}[a] \mathrm{P}$, the second contained $\mathrm{B}[a] \mathrm{P}$ and the last contained later-eluting PAHs. The selectivity and 21 recovery of the system was investigated using extracts of Stockholm air PM samples. The overall recovery for all 22 PAHs was approximately $80 \%$, and the system proved to be selective, as it removed $94 \%$ of $\mathrm{B}[a] \mathrm{P}$ and less than $3 \%$ 23 of benzo[b]fluoranthene from the complex PAH mixture. Exposing human cells to blanks generated by the 24 fractionation system did not induce cytotoxicity or DNA damage signalling. In conclusion, the online HPLC system 25 was selective for $\mathrm{B}[a] \mathrm{P}$ fractionation whilst minimising run-to-run variation and allowing repeated fractionations for 26 larger samples due to its relatively short run time

27 Keywords: automation, benzo[a]pyrene, fractionation, PAH, pyrenylethyl, synergism 
Benzo[a]pyrene $(\mathrm{B}[a] \mathrm{P})$ belongs to the group of chemical compounds referred to as polycyclic aromatic hydrocarbons (PAHs) [1]. Recent studies on $\mathrm{B}[a] \mathrm{P}$ have revealed its potential role as a cancer inducer in human skin breast cells, and neurotoxic effects resulting from exposure to $\mathrm{B}[a] \mathrm{P}$ have been investigated in Sprague-Dawley rat $[2-4]$.

$\mathrm{B}[a] \mathrm{P}$ is currently the only $\mathrm{PAH}$ classified as carcinogenic to humans, whilst other PAHs, such as dibenz[a,h]anthracene, several dibenzopyrenes and benzofluoranthenes, have been classified as "probably or possibly carcinogenic to humans" based on studies using various in vitro and in vivo experimental models [1]. $\mathrm{B}[a] \mathrm{P}$ is the key compound used in the two main approaches for assessing the carcinogenic risk of human exposure to PAHs in ambient air $[5,6]$. In the epidemiological approach, $\mathrm{B}[a] \mathrm{P}$ is used as a surrogate for the entire complex mixture of PAHs together with occupational epidemiological data to determine quantitative risk estimates. The World Health Organisation has derived a unit risk value based on the increased risk for lung cancer in coke-oven workers [7,8]. However, a major weakness of this methodology is that it assumes that the relative PAH concentration profiles are stable between different exposure situations. The other method for risk assessment utilises animal experiment data on the carcinogenic potency of individual PAHs relative to that of $\mathrm{B}[a] \mathrm{P}$. These relative potency values, referred to as toxic equivalency factors (TEFs) or potency equivalency factors (PEFs), are then multiplied with the concentration of the respective $\mathrm{PAH}$, creating a product called a $\mathrm{B}[a] \mathrm{P}$ equivalent [5]. Summing the $\mathrm{B}[a] \mathrm{P}$ equivalents and multiplying by the potency of $\mathrm{B}[a] \mathrm{P}$ gives a risk estimate [5]. One major assumption using the TEF/PEF scheme is the additivity of individual risks, implying that interactions among the different PAHs in complex exposure situations do not modulate the carcinogenic potential of the PAH mixture. Chemical interactions can be additive, synergistic, potentiative or antagonistic when two or more chemicals are combined. That is, the toxicity of a PAH mixture can increase or decrease depending on the corresponding interactions, which can lead to under- or overestimations of its toxicological effect [9]. Previous studies have reported synergistic [1015] and antagonistic effects [16-18] of complex PAH mixtures in different biological systems, and the risk of underestimating the carcinogenic potential by the use of TEFs/PEFs has been demonstrated in several in vitro and in vivo studies [10-12,14,19,20]. Moreover, a newer approach to environmental cancer research, in which synergistic effects are included as one of the factors in the study of mixtures, has been proposed by the US President's Cancer Panel [21]. As a result, testing the toxicity of chemical mixtures or environmental samples has been increasing in comparison to using a single compound [21].

Sample preparation methods for toxicity testing are crucial, and various fractionation methods have been established to obtain cleaner and more defined fractions. Most of the techniques involve initial crude and subsequent fine fractionations, followed by chemical analysis. These methods have several different names, including bioassaydirected chemical analysis [22], bioassay-directed fractionation [23-26], toxicity-based fractionation [27] and effectdirected fractionation [28]. Previous studies have been conducted using a similar procedure. First, sample extracts were treated with silica gel or cleaned up with solid phase extraction (SPE). Then the eluates were subjected to

64 liquid chromatography (LC) to obtain refined fractions and sub-fractions, if further separation was necessary. Then, 65 an aliquot was analysed for chemical content using high performance LC with ultra-violet and/or fluorescence 
detection (HPLC-UV/FLD), or gas chromatography/mass spectrometry (GC/MS), while another aliquot was designated for toxicity tests [22-30]. Other studies have been conducted using solvent extraction methods with various combinations of organic solvents, or by SPE using different eluting conditions [31,32]. Additionally, an automated normal-phase LC (NPLC) fractionation system for PAHs in sediments using three LC columns was presented by Varel et al. [33].

Despite high-resolution fractionation steps, the final solution is often a mixture of several compounds with similar chemical properties. As a result, further investigations are required to narrow the candidates and identify the main compounds contributing to toxicological effects. Of the various chromatographic techniques used for selective fractionation, HPLC is considered to be a good tool, especially when appropriate HPLC columns are used to maximise the separation efficiency. Silica-based columns modified with amino, nitro, cyano, alkylhydroxy, alkylamino and alkylcyano moiety have been used for PAH analysis to remove aliphatic hydrocarbons and fractionate PAHs, based on the number of aromatic rings [34-37]. Polymeric $\mathrm{C}_{18}$ columns were found to have unique selectivity for PAHs and a reversed-phase LC (RPLC) with FLD has replaced traditional NPLC for both preparative and quantitative $\mathrm{PAH}$ analysis [38-41]. Polymeric $\mathrm{C}_{18}$ columns selectively retain isomeric PAHs, as explained in the "slot model" in which PAH retention is highly dependent on the molecular shape of the PAHs, that is, their ability to

81 fit in the slit-like holes of the stationary phase [42]. However, fractions from an RPLC system normally contain water, which hinders fast evaporation during the preparation of samples for toxicity tests.

The ability to investigate the effects of interactions between $\mathrm{B}[a] \mathrm{P}$ and other compounds in complex mixtures by selective inclusion/exclusion would be of significant benefit for future toxicity analyses. Thus, the aim of the present study was to develop an NPLC system for $\mathrm{B}[a] \mathrm{P}$-specific fractionation. The online system was equipped with an autosampler and switching valves controlled by a computer for precise and reproducible fractionation. The system was optimised using PAH standards and finally evaluated for separation efficiency and recoveries using a complex PAH mixture extracted from air particulate matter (PM) collected from the urban atmosphere of Stockholm.

92 Solvents used for extraction, sample preparation and analysis were hexane, acetone and toluene (HPLC grade, 93 Walkerburn Scotland) and dodecane (anhydrous, $\geq 99 \%$, Sigma-Aldrich, St. Louis, MO, USA). All PAH standards

94 and internal standards (ISs) used in the present study are specified with their abbreviation, CAS number, supplier, 95 purity, molecular formula and molecular weight in the Supplementary data (S) Table S1.

\section{$96 \quad 2.2$ Air sampling}


97 Air PM was collected at the rooftop level (22 metres from the ground) of the Arrhenius building at Stockholm 98 University [43]. Sampling was performed on a fluorocarbon coated glass fibre filter $(\varnothing=235 \mathrm{~mm}$, Fiberfilm Filters,

99 Pallflex, Pall Corporation, Putnam, CT, USA) using an in-house constructed pump device equipped with a flow 100 meter. The filter was desiccated for at least 24 hours before and after sampling, wrapped in aluminium foil and 101 stored at $-20{ }^{\circ} \mathrm{C}$ until extraction. The total volume of sampled air was $5141 \mathrm{~m}^{3}$, and the average sampling rate was $10272.5 \mathrm{~m}^{3} / \mathrm{hr}$. The sampling was performed in January 2013 (January 18-21) to avoid possible pollen introduction.

\section{$103 \quad 2.3$ Extraction and SPE clean-up}

104 The sampled filter was extracted with toluene for $5 \times 30 \mathrm{~min}$ using pressurised liquid extraction (ASE 200 105 Accelerated Solvent Extraction System, Dionex Co., Sunnyvale, CA, USA). Then, $0.6 \mathrm{~mL}$ of the extract, 106 corresponding to $56 \mathrm{~m}^{3}$, was applied to a silica SPE column (100 mg, IST Isolute, Biotage, Cardiff, UK) and eluted 107 with $2 \mathrm{~mL}$ of hexane to remove polar compounds and obtain a PAH enriched fraction. The final hexane eluate was 108 gently evaporated to $20-50 \mu \mathrm{L}$ under a nitrogen stream before online HPLC fractionation. The extraction and SPE 109 clean-up procedures are described in detail elsewhere [44].

111 A schematic illustration of the automated system for B $[a]$ P-specific fractionation is shown in Fig. S1.

112 The chromatographic system comprised an HPLC pump (Varian 9001, Varian Inc., Palo Alto, CA, USA), an 113 autosampler (CMA/240, CMA Microdialysis AB, Stockholm, Sweden), two 2-(1-pyrenyl)ethyl (PYE) columns 114 (Cosmosil PYE, $150 \times 4.6 \mathrm{~mm}, 5$ m , Nacalai Tesque Inc., Kyoto, Japan) and a UV detector (Varian 9050, Varian 115 Inc., Palo Alto, CA, USA). In addition, two position-switching valves with 3 (valve 2 and 3) and 4 (valve 1) ports 116 (Valco Instruments Co. Inc., Houston, TX, USA) were used to change the column flow and collect the fractions into 117 appointed test tubes. The autosampler was controlled with the CMA/200 v2.02 software (CMA Microdialysis AB, 118 Stockholm, Sweden) and all hardware communications, including sample injection, valve switching and monitoring 119 of the UV signal, were regulated by a personal computer equipped with the ELDS Win v1.1 software 120 (Chromatography Data Systems AB, Svartsjö, Sweden). The temperature of the columns was set to $30{ }^{\circ} \mathrm{C}$ with a 121 column oven (Croco-cil, Cluzeau Info Labo, Sainte-Foy-La-Grande, France) during operation to minimise run-to122 run retention time variation.

$123 \quad 2.5 \mathrm{LC}-\mathrm{GC} / \mathrm{MS}$ analysis

124 The collected fractions were spiked with ISs and the volume was reduced to $100 \mu \mathrm{L}$ under a gentle stream of 125 nitrogen. Then, the samples were transferred to micro vials for LC-GC/MS analysis. Analytical parameters are 126 described in detail elsewhere [45]. 
130 A test solution in hexane was prepared by mixing $\mathrm{B}[a] \mathrm{P}$ with six structural isomers commonly encountered in 131 environmental samples: benzo[a]fluoranthene $(\mathrm{B}[a] \mathrm{F})$, benzo $[b]$ fluoranthene $(\mathrm{B}[b] \mathrm{F})$, benzo[j]fluoranthene $(\mathrm{B}[j] \mathrm{F})$, 132 benzo $[k]$ fluoranthene $(\mathrm{B}[k] \mathrm{F})$, benzo[e]pyrene $(\mathrm{B}[e] \mathrm{P})$ and perylene $($ Per $)$. Initially, a nitrophenylpropyl $\left(\mathrm{NO}_{2}\right)$ silica 133 column $(4.0 \times 125 \mathrm{~mm}, 5 \mu \mathrm{m}$, Phenomenex, Torrance, CA, USA) was evaluated for the separation of the seven 134 PAHs with molecular weights of 252 Da using hexane as the mobile phase. Hexane was selected as the mobile 135 phase because it is a common solvent in NPLC systems and it has been recommended for increasing the resolution 136 of PAHs [30]. However, insufficient separation was achieved using this set-up, and a PYE column was investigated 137 to determine if it could improve the separation. Previously, this type of column has mainly been used for the 138 separation of polychlorinated biphenyls (PCBs) and polychlorinated dibenzo-p-dioxins (PCDDs) [46-49]. Studies on 139 PAH analysis using PYE columns are scarce, but this type of column was previously used in HPLC/UV analysis for 140 the quantitation of PCBs and PAHs [50]. The retention of analytes on the PYE column is due to the donor-acceptor 141 interaction in which the electron-rich pyrenyl group on the column function as electron donor to the analytes via $\pi$ - $\pi$ 142 charge transfer, resulting in increased retention of planar analytes over non-planar ones owing to less steric

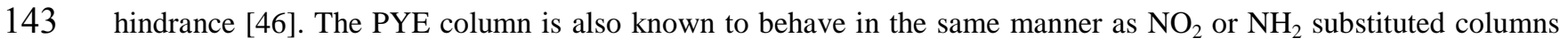
144 when used for PAH analysis in NPLC mode, that is, it separates PAHs based on their ring size but with less group 145 separation efficiency than $\mathrm{NO}_{2}$ or $\mathrm{NH}_{2}$ substituted columns [51]. However, the PYE column is considered to be 146 more suitable for isomer analysis [51]. Therefore, the PYE column was chosen in the present study because B[a]P 147 separation from its isomers was the main issue rather than separation according to number of aromatic rings. The 148 separation of the seven PAHs was improved and performed in a shorter time using the PYE column than with the

$149 \mathrm{NO}_{2}$ column. However, $\mathrm{B}[a] \mathrm{P}$ partially co-eluted with $\mathrm{B}[a] \mathrm{F}$ and $\mathrm{B}[b] \mathrm{F}$ as shown in Fig. 1, A. Peaks were identified 150 by comparing the retention times obtained from the injection of individual PAHs.

1513.2 Serial column separation

152 Based on the enhanced separation observed on the PYE column compared to the $\mathrm{NO}_{2}$ column, further exploration 153 using the PYE column in the LC system was carried out to attempt to obtain baseline resolution of B[a]P from the 154 other 252 Da molecular weight isomers. The peak capacity of an LC column is usually increased by the introduction 155 of one or more columns into the existing set-up, either comprehensively or serially [52]. A serially coupled LC 156 system is preferred compared to a comprehensive LC set-up because the peak capacity is greatly dependent on the 157 orthogonality of the columns and requires relatively long separation times [52]. Previously reported studies have 158 applied the serial column separation concept to complex samples of essential oils and digested proteins [53,54]. 159 Accordingly, two PYE columns with the same dimensions were connected in series to reduce the co-elution of $160 \mathrm{~B}[a] \mathrm{P}$ with $\mathrm{B}[a] \mathrm{F}$ and $\mathrm{B}[b] \mathrm{F}$. The separation of the seven $252 \mathrm{Da}$ PAHs was enhanced using the PYE-PYE serial 161 column set-up when compared to the system using one PYE column (Fig. 1, A and B). 
163 A UV chromatogram generated from injection of a standard solution containing 41 PAHs and 6 ISs in hexane on the 164 automated B[a]P-specific online HPLC fractionation system is shown in Fig. 2 and depicts the time points for 165 collection of the different fractions. $\mathrm{B}[a] \mathrm{F}$ and $\mathrm{B}[j] \mathrm{F}$ were only used to prepare the test solution of the $252 \mathrm{Da}$ PAHs 166 and were not included in the standard PAH solution.

167 The large peak at the beginning of the chromatogram $(5 \mathrm{~min})$ is from toluene, which was used as the solvent for 168 preparing the PAH stock solution. Each fractionation step is described in Fig. S2, A-F, in which the flow paths are 169 differently coloured. The red line indicates the column flow before the backflush and the reversed column flow after 170 the backflush is indicated with a blue line.

171 The system began in standby mode, with the mobile phase flowing through the columns and valves into the waste 172 bottle connected to valve V3 (Fig. S2, A). After injection, the system was put in standby mode for approximately six 173 minutes to direct mobile phase and residual toluene to waste (W1), then valve V3 was switched to collect PAHs 174 eluting earlier than $\mathrm{B}[a] \mathrm{P}$ in fraction 1 (F1) (Fig. S2, B). Just before the elution of $\mathrm{B}[a] \mathrm{P}$, the system began 175 collecting fraction 2 (F2) by diverting the flow through valve V2 (Fig. S2, C).

176 Then, the column flow was reversed while valve V2 was kept at the same position to complete the collection of 177 residual $\mathrm{B}[a] \mathrm{P}$ in the tubing between the UV detector and the collecting tube (Fig. S2, D). Excess mobile phase was 178 sent to the waste (W2) through valve V3 (Fig. S2, E), and then the backflush peak containing PAHs eluting later 179 than $\mathrm{B}[a] \mathrm{P}$ was collected in fraction $3(\mathrm{~F} 3)$ (Fig. S2, F). After finishing the collection, the system was returned to 180 standby mode to prepare for the next run (Fig. S2, A). All valve switching times are presented in Table S2 and the 181 run time for one total cycle of fractionation was 30 minutes.

183 SPE cleaned-up extracts of Stockholm air PM were fractionated on the system in triplicate. A chromatogram 184 generated from an injection of a Stockholm air PM extract is presented in Fig. 3.

185 Valve switching times for collecting F3 were adjusted to resolve peak broadening due to sample complexity. 186 GC/MS chromatograms obtained in selected ion monitoring (SIM) mode, from which ions with $\mathrm{m} / \mathrm{z} 252$ were 187 extracted to assess the separation selectivity of the $\mathrm{B}[a] \mathrm{P}$-specific online HPLC fractionation system (displayed in 188 Fig. 4), are shown in Figs. S3, S4 and S5. The first fraction, F1 contained all four benzofluoranthenes but no 189 detectable amount of $\mathrm{B}[a] \mathrm{P}$. A minor amount of $\mathrm{B}[b] \mathrm{F}(2 \%)$ was present in fraction $\mathrm{F} 2 . \mathrm{B}[e] \mathrm{P}$ and Per peaks were 190 observed in fraction $\mathrm{F} 3$, along with a small amount of $\mathrm{B}[a] \mathrm{P}(6 \%)$.

191 Waste was collected before F1 (W1) and between F2 and F3 (W2) (Fig. S6) to confirm that no PAHs were lost in 192 the waste. Chromatograms of fractions from injections of a blank sample and hexane are shown in Figs. S7 and S8. 193 Two system peaks were observed in GC/MS chromatograms from sample waste fractions and from the fractions 
generated by blank and hexane injections. The system peaks did not interfere with other PAH peaks in the GC/MS

195 chromatogram. GC/MS full scan spectra of the system peaks are shown in Fig. S9. A NIST library search found no 196 relevant matches for these peaks, so another GC/MS system with different chromatographic conditions (Table S3) 197 was used to analyse the eluate from the $\mathrm{B}[a] \mathrm{P}$-specific online HPLC fractionation system. Three major peaks were detected (Fig. S10) and matched with three different substituted pyrenes from the NIST library. The highest ranked hits for each peak were 1-hydroxypyrene, 1-pyrene-carboxaldehyde and 1-acetylpyrene, respectively. These compounds most likely originate from the pyrenyl moiety in the stationary phases of the HPLC columns (Fig. S11). In addition, no peaks were found in the GC/MS chromatograms when the eluate collected from the system without PYE columns was injected, which eliminates the injector, HPLC pump, valves and tubing as possible sources of the system peaks.

3.5 Toxicological testing of chromatographic blanks

The blank eluates generated from the fractionation system were applied to toxicity tests aimed at evaluating DNA damage signalling and cytotoxicity (methods are described in further detail in S7). Chk1 and H2AX are key signal transduction proteins activated by phosphorylation in response to DNA damage resulting from cellular exposure to PAHs [10]. The results of the present study showed no phosphorylation of Chk1 or H2AX in human HepG2 cells following exposure to the eluates whereas a 17- and 2-fold induction of Chk1 and H2AX, respectively, was observed in response to $3 \mu \mathrm{M}$ B $[a] \mathrm{P}$ (Fig. S12, A-C). No effects were observed on the levels of p53 protein in any of the exposures (Fig. S12, A and D). Furthermore, no effects were observed on cell viability (Fig. S12, E). Taken together, these data demonstrate that the blank eluates generated from the fractionation system are non-cytotoxic to cells and do not induce DNA damage related-signalling.

3.6 Recovery of PAHs and separation efficiency of $\mathrm{B}[a] \mathrm{P}$

215 Quantitative PAH results are summarised in Fig. 5. Non-fractionated samples were prepared by spiking ISs into the 216 SPE cleaned-up samples, while the collected fractions were spiked with ISs after the fractionation process. The 217 average recovery of PAHs in the fractionation system was approximately 80\%, varying from 61 to $105 \%$. Main 218 losses were due to residue remaining in the micro vial and injection needle. Therefore, the PAH concentrations of 219 fractions generated on the $\mathrm{B}[a] \mathrm{P}$-specific online HPLC fractionation system should be re-analysed prior to toxicological tests to establish more accurate dose-responses.

221 A relative comparison between different fractions was performed to investigate the separation efficiency of the $222 \mathrm{~B}[a] \mathrm{P}$-specific online HPLC fractionation system. As shown in Fig. 6, 94\% of B $[a] \mathrm{P}$ was found in F2 and $6 \%$ was 223 found in F3, but no detectable amount was found in F1. The amount found in F3 could be explained by peak tailing 224 of $\mathrm{B}[a] \mathrm{P}$ on the LC columns, that is, a slight overlap with the following $\mathrm{B}[e] \mathrm{P}$ peak. The standard deviations of the 225 mean values of the relative amount were less than $1 \%$. In the fractionation, the valve switching times were set such 226 that greater than $90 \%$ of $\mathrm{B}[a] \mathrm{P}$ could be collected while minimising the introduction of other PAHs in the same fraction. In addition, full scan GC/MS analysis of blank, non-fractionated and fractionated samples were conducted 
in order to examine co-eluting compounds in the same region of chromatograms as the 252 Da PAHs (Fig. S13). Three unknown compounds (peak 5, 6 and 10) were detected in the chromatogram of the non-fractionated sample. Peak 6 and 10 could potentially be methylated isomers of 252 Da PAHs because their mass specta features a molecular ion at $m / z$ 266. Peak 6 was also detected in F1, but no visible peaks were detected in F2 and F3 (Fig. S13, F1-F3). Methylated PAHs usually elute after the native PAHs on the PYE column in NPLC mode [55], but some methylated PAHs such as 1-methyl perylene elute earlier than their native forms [56]. Among possible methylated isomers, methylated $\mathrm{B}[a]$ Ps are of concern related to their mutagenicity [57-59] though they have been reported to be present at relatively low levels compared to that of $\mathrm{B}[a] \mathrm{P}$ in coal tar [60]. On the assumption of peak 6 being one isomer of methylated $\mathrm{B}[a] \mathrm{P}$, its presence in $\mathrm{F} 1$ might contribute to the toxicity of the $\mathrm{B}[a] \mathrm{P}$-free fraction. However, the contribution to the toxicity is assumed to be low because the peak is relatively small.

The PAH concentrations determined in the initial toluene extracts (Table S4) were comparable to those from a previous study conducted at the same sampling site [10]. The results of the present study demonstrated that the $\mathrm{B}[a] \mathrm{P}$-specific online HPLC fractionation system can selectively remove $\mathrm{B}[a] \mathrm{P}$ from a complex Stockholm air PM extract. In addition, this system set-up can easily be modified by changing columns, mobile phase and valve switching times to selectively remove other PAHs of interest.

245 The present study established an online HPLC fractionation system for the selective removal of B[a]P from the complex PAH mixture of an air PM extract using two PYE columns in series. The system showed a high selectivity, removing $94 \%$ of $\mathrm{B}[a] \mathrm{P}$ and less than $3 \%$ of $\mathrm{B}[b] \mathrm{F}$ from the complex mixture. One fractionation cycle requires only 30 minutes, which makes it possible to do repeated fractionations for larger samples. The system is simple and easy to re-construct in a normal chromatography lab, because it only requires analytical scale tubing, a pump, an injector, columns and a detector. More fractions can easily be obtained by adding additional switch valves or by introducing fraction collectors to the current system. In addition, automatic fractionation minimises the exposure of operators to toxicants and increases the precision and time efficiency. Sample overloading can be avoided by repeated fractionations and the system can be modified by changing mobile phase and columns, allowing for selective fractionation of other target compounds and matrices. The mixture as a whole or lacking $\mathrm{B}[a] \mathrm{P}$ obtained from the system can assist in the evaluation of $\mathrm{B}[a] \mathrm{P}$ toxicity by considering interactions between $\mathrm{B}[a] \mathrm{P}$ and other co-existing compounds. Blanks generated on the fractionation system were not cytotoxic to cells and did not induce DNA damage-related signalling. In conclusion, this system is a useful tool for elucidating the toxicological effects of

$258 \mathrm{~B}[a] \mathrm{P}$ in complex $\mathrm{PAH}$ mixtures. Furthermore, the mixture-based toxicity evaluation of not only $\mathrm{B}[a] \mathrm{P}$, but also other target compounds, could improve current methods for risk assessment. 
Acknowledgements

262 The authors are grateful to Ioannis Sadiktsis for assistance with GC/MS analyses. This work was supported by 263 Stockholm University, Karolinska Institutet and the Swedish Research Council Formas (R\&D project No. 2012264 478).

265 Appendix A. Supplementary data

266 Supplementary data associated with this article can be found, in the online version, at 267 http://dx.doi.org/10.1016/j.chroma.xxxx.xx.xxx.

References

[1] IARC, Monographs on the Evaluation of Carcinogenic Risks to Humans: Some Non-heterocyclic Polycyclic Aromatic Hydrocarbons and Some Related Exposures, International Agency for Research on Cancer (IARC), Lyon, 2712010.

272 [2] J. Brinkmann, K. Stolpmann, S. Trappe, T. Otter, D. Genkinger, U. Bock, M. Liebsch, F. Henkler, C. Hutzler, A. 273 Luch, Toxicol. Sci. 131 (2013) 351.

274 [3] Y. Chen, C. Huang, C. Bai, H. Gao, R. Ma, X. Liu, Q. Dong, Toxicology 304 (2013) 167.

[4] S. Cheng, Y. Xia, J. He, X. Liu, X. Chen, Y. Ding, Y. Wang, B. Peng, B. Tu, Environ. Toxicol. Phar. 36 (2013)

277 [5] M. Pufulete, J. Battershill, A. Boobis, R. Fielder, Regul. Toxicol. Pharm. 40 (2004) 54.

278 [6] C.E. Boström, P. Gerde, A. Hanberg, B. Jernström, C. Johansson, T. Kyrklund, A. Rannug, M. Törnqvist, K. 279 Victorin, R. Westerholm, Environ. Health Perspect. 110 (Suppl. 3) (2002) 451.

280 [7] WHO, Air Quality Guidelines for Europe, World Health Organization (WHO) Regional Publications, 281 Copenhagen, 1987.

282 [8] WHO, Air Quality Guidelines for Europe, Second Edition, World Health Organization (WHO) Regional Office 283 for Europe, Copenhagen, 2000.

284 [9] D. Delistraty, Toxicol. Environ. Chem. 64 (1997) 81.

285 [10] I.W.H. Jarvis, C. Bergvall, M. Bottai, R. Westerholm, U. Stenius, K. Dreij, Toxicol. Appl. Pharmacol. 266 286 (2013) 408.

287 [11] Å Mattsson, S. Lundstedt, U. Stenius, Environ. Mol. Mutagen. 50 (2009) 337.

288 [12] M. Niziolek-Kierecka, K. Dreij, S. Lundstedt, U. Stenius, Chem. Res. Toxicol. 25 (2012) 862.

289 [13] Y.C. Staal, D.G. Hebels, M.H. van Herwijnen, R.W. Gottschalk, F.J. van Schooten, J.H. van Delft, 290 Carcinogenesis 28 (2007) 2632.

291 [14] A. Tarantini, A. Maitre, E. Lefebvre, M. Marques, C. Marie, J.L. Ravanat, T. Douki, Mutat. Res. - Fund. Mol. 292 M. 671 (2009) 67. 
[15] A. Tarantini, A. Maître, E. Lefèbvre, M. Marques, A. Rajhi, T. Douki, Toxicology 279 (2011) 36.

[16] L.A. Courter, A. Luch, T. Musafia-Jeknic, V.M. Arlt, K. Fischer, R. Bildfell, C. Pereira, D.H. Phillips, M.C. 295 Poirier, W.M. Baird, Cancer Lett. 265 (2008) 135.

296 [17] B. Mahadevan, C.P. Marston, A. Luch, W.M. Dashwood, E. Brooks, C. Pereira, J. Doehmer, W.M. Baird, Int. 297 J. Cancer 120 (2007) 1161.

298 [18] C.P. Marston, C. Pereira, J. Ferguson, K. Fischer, O. Hedstrom, W.M. Dashwood, W.M. Baird, Carcinogenesis $29922(2001) 1077$.

300 [19] D.W. Gaylor, S.J. Culp, L.S. Goldstein, F.A. Beland, Risk Anal. 20 (2000) 81.

301 [20] L.K. Siddens, A. Larkin, S.K. Krueger, C.A. Bradfield, K.M. Waters, S.C. Tilton, C.B. Pereira, C.V. Löhr, 302 V.M. Arlt, D.H. Phillips, D.E. Williams, W.M. Baird, Toxicol. Appl. Pharmacol. 264 (2012) 377.

303 [21] NCI, Reducing Environmental Cancer Risk: What We Can Do Now, U.S. Department of Health and Human 304 Services (HHS), National Institutes of Health, National Cancer Institute (NCI) (2010)

305 [22] D. Schuetzle, J. Lewtas, Anal. Chem. 58 (1986) 1060A.

306 [23] M.G. Nishioka, C.C. Howard, D.A. Contos, L.M. Ball, J. Lewtas, Environ. Sci. Technol. 22 (1988) 908.

307 [24] J. Arey, W.P. Harger, D. Helmig, R. Atkinson, Mutat. Res. 281 (1992) 67.

308 [25] C.H. Marvin, B.E. McCarry, J.A. Lundrigan, K. Roberts, D.W. Bryant, Sci. Total Environ. 231 (1999) 135.

309 [26] S. Biselli, N. Reineke, N. Heinzel, U. Kammann, S. Franke, H. Hühnerfuss, N. Theobald, J. Soils Sediments 5 310 (2005) 171.

311 [27] P.A. Kosian, E.A. Makynen, P.D. Monson, D.R. Mount, A. Spacie, O.G. Mekenyan, G.T. Ankley, Environ. 312 Toxicol. Chem. 17 (1998) 1021.

313 [28] W. Brack, K. Schirmer, T. Kind, S. Schrader, G. Schüürmann, Environ. Toxicol. Chem. 21 (2002) 2654.

314 [29] T. Alsberg, M. Strandell, R. Westerholm, U. Stenberg, Environ. Int. 11 (1985) 249.

315 [30] W. Brack, T. Kind, H. Hollert, S. Schrader, M. Möder, J. Chromatogr. A 986 (2003) 55.

316 [31] H.F. Wesp, X. Tang, R. Edenharder, Mutat. Res. 472 (2000) 1.

317 [32] R.E. Cochran, N. Dongari, H. Jeong, J. Beránek, S. Haddadi, J. Shipp, A. Kubátová, Anal. Chim. Acta 740 318 (2012) 93.

319 [33] U. Lübcke-von Varel, G. Streck, W. Brack, J. Chromatogr. A 1185 (2008) 31.

320 [34] S.A. Wise, S.N. Chesler, H.S. Hertz, L.R. Hilpert, W.E. May, Anal. Chem. 49 (1977) 2306.

321 [35] C. Östman, A. Colmsjö, Chromatographia 25 (1988) 25.

322 [36] E.P. Lankmayr, K. Müller, J. Chromatogr. A 170 (1979) 139.

323 [37] J. Chmielowiec, A.E. George, Anal. Chem. 52 (1980) 1154.

324 [38] W.E. May, S.A. Wise, Anal. Chem. 56 (1984) 225. 
[39] L.C. Sander, S.A. Wise, Anal. Chem. 56 (1984) 504.

326 [40] L.C. Sander, S.A. Wise, J. Chromatogr. A 316 (1984) 163.

327 [41] L.C. Sander, S.A. Wise, Anal. Chem. 59 (1987) 2309.

328 [42] S.A. Wise, L.C. Sander, J. High Res. Chromatog 8 (1985) 248.

329 [43] C. Bergvall, R. Westerholm, Environ. Sci. Technol. 41 (2007) 731.

330 [44] C. Bergvall, R. Westerholm, Anal. Bioanal. Chem. 391 (2008) 2235.

331 [45] I. Sadiktsis, J.H. Koegler, T. Benham, C. Bergvall, R. Westerholm, Fuel 115 (2014) 573.

332 [46] P. Haglund, L. Asplund, U. Järnberg, B. Jansson, J. Chromatogr. A 507 (1990) 389.

333 [47] K. Kimata, K. Hosoya, T. Araki, N. Tanaka, E.R. Barnhart, L.R. Alexander, S. Sirimanne, P.C. McClure, J.

334 Grainger, D.G. Patterson Jr., Anal. Chem. 65 (1993) 2502.

335 [48] M.M. Krahn, G.M. Ylitalo, J. Buzitis, C.A. Sloan, D.T. Boyd, S.-L. Chan, U. Varanasi, Chemosphere 29 (1994) 336117.

337 [49] K. Kimata, K. Hosoya, H. Kuroki, N. Tanaka, J.R. Barr, P.C. McClure, D.G. Patterson Jr., E. Jakobsson, A. 338 Bergman, J. Chromatogr. A 786 (1997) 237.

339 [50] C. Nerín, C. Domeño, Analyst 124 (1999) 67.

340 [51] U.L. Nilsson, A.L. Colmsjö, Chromatographia 34 (1992) 115.

341 [52] E. Blahová, P. Jandera, F. Cacciola, L. Mondello, J. Sep. Sci. 29 (2006) 555.

342 [53] M. Herrero, F. Cacciola, P. Donato, D. Giuffrida, G. Dugo, P. Dugo, L. Mondello, J. Chromatogr. A 1188 343 (2008) 208.

344 [54] P. Donato, P. Dugo, F. Cacciola, G. Dugo, L. Mondello, J. Sep. Sci. 32 (2009) 1129.

345 [55] L.C. Sander, R.M. Parris, S.A. Wise, Anal. Chem. 63 (1991) 2589.

346 [56] S.A. Wise, L.C. Sander, J. Chromatogr. A. 514 (1990) 111.

347 [57] O.G. Fahmy, M.J. Fahmy, Cancer Res. 33 (1973) 302.

348 [58] R.P. Iyer, J.W. Lyga, J.A. Secrist, G.H. Daub, T.J. Slaga, Cancer Res. 40 (1980) 1073.

349 [59] R. Santella, T. Kinoshita, A.M. Jeffrey, Mutat. Res. 104 (1982) 209.

350 [60] P. Garrigues, J. Bellocq, S.A. Wise, Fresen. J. Anal. Chem. 336 (1990) 106. 
Figure captions

353 Fig. 1. HPLC/UV chromatogram of a PAH standard solution injected on (A) a PYE column and (B) a serial PYE 354 column set-up. (A) Conditions: hexane $100 \%$, flow rate $0.7 \mathrm{~mL} / \mathrm{min}$, ambient column temperature, UV detection at $355254 \mathrm{~nm}$, (B) Conditions: hexane $100 \%$, flow rate $0.8 \mathrm{~mL} / \mathrm{min}$, column temperature at $30{ }^{\circ} \mathrm{C}$, UV detection at 254 $356 \mathrm{~nm}$. UV detector sensitivity of 0.02 absorbance units full scale (AUFS). AU: absorbance units. Ant*: Anthracene 357 was added to the mixture as a retention indicator.

358 Fig. 2. HPLC/UV chromatogram of the $41 \mathrm{PAH}$ standard solution from the online HPLC fractionation system: (A) 359 full-scale chromatogram, (B) enlarged chromatogram depicting fractionation points. Conditions: two PYE columns $360(150 \times 4.6 \mathrm{~mm}, 5 \mu \mathrm{m})$, hexane $100 \%$, flow rate $0.8 \mathrm{~mL} / \mathrm{min}$, column temperature at $30{ }^{\circ} \mathrm{C}$, UV detection at $254 \mathrm{~nm}$, 361 UV detector sensitivity of 0.02 AUFS. AU: absorbance units, F: fraction, W: waste.

362 Fig. 3. HPLC/UV chromatogram of an injection of a Stockholm air PM extract on the B $[a] \mathrm{P}$-specific online HPLC 363 fractionation system. Instrumental conditions are described in Fig. 2.

364 Fig. 4. GC/MS extracted ion chromatograms $(\mathrm{m} / \mathrm{z}, 252)$ of the fractions generated from an injection of a Stockholm 365 air PM extract on the $\mathrm{B}[a] \mathrm{P}$-specific online HPLC fractionation system.

366 Fig. 5. PAH concentrations determined in a Stockholm air PM extract and in the fractions collected from the B $[a] \mathrm{P}-$ 367 specific online HPLC fractionation system. Error bars show one standard deviation from the mean value $(n=3)$. 368 Compound abbreviations are shown in Table S1.

369 Fig. 6. Relative abundance of $252 \mathrm{Da}$ molecular weight PAHs in the fractions generated by the B $[a] \mathrm{P}$-specific online 370 HPLC fractionation system. Error bars show one standard deviation from the mean value $(n=3)$. 


\section{Figures}

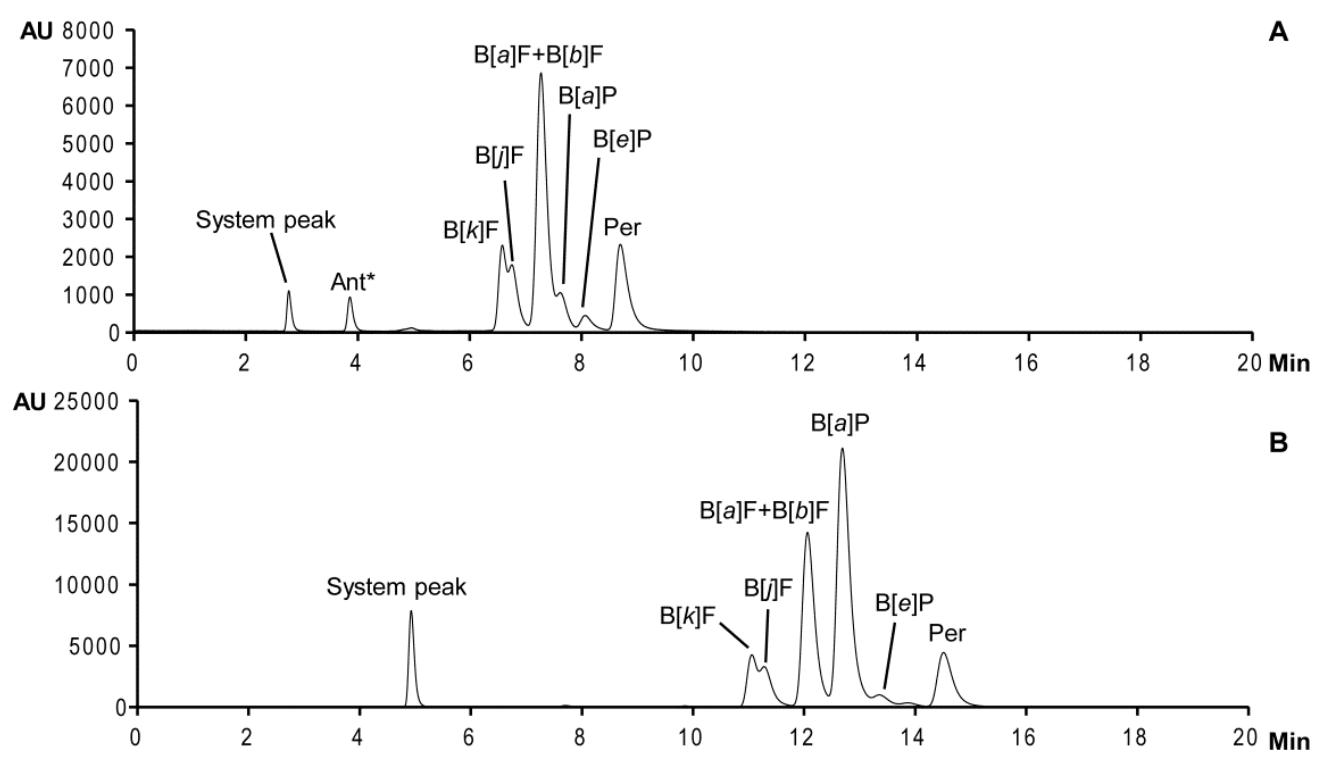

Fig. 1. HPLC/UV chromatogram of a PAH standard solution injected on (A) a PYE column and (B) a serial PYE column set-up. (A) Conditions: hexane $100 \%$, flow rate $0.7 \mathrm{~mL} / \mathrm{min}$, ambient column temperature, UV detection at $254 \mathrm{~nm}$, (B) Conditions: hexane $100 \%$, flow rate $0.8 \mathrm{~mL} / \mathrm{min}$, column temperature at $30^{\circ} \mathrm{C}$, UV detection at 254 $\mathrm{nm}$. UV detector sensitivity of 0.02 absorbance units full scale (AUFS). AU: absorbance units. Ant*: Anthracene was added to the mixture as a retention indicator. 


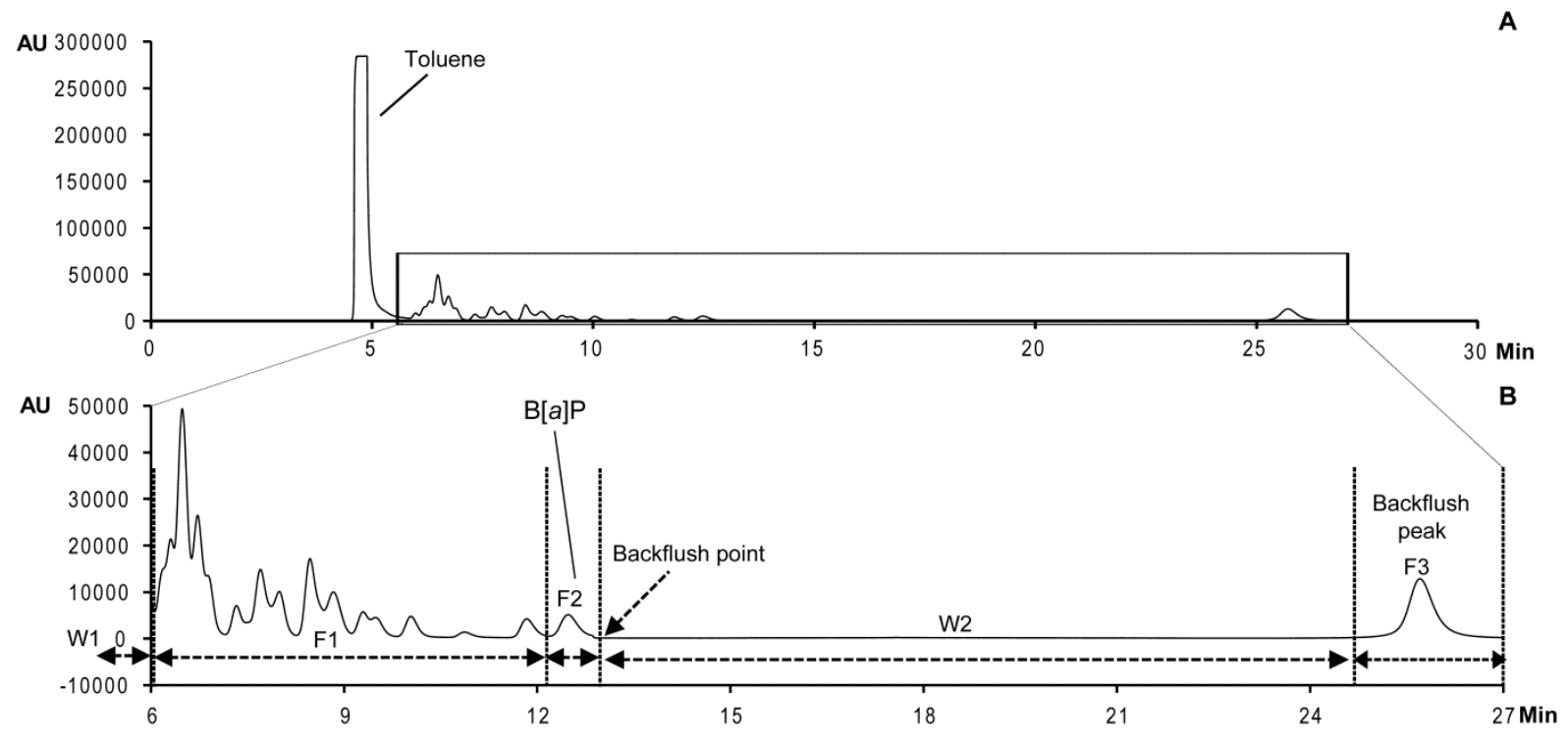

Fig. 2. HPLC/UV chromatogram of the $41 \mathrm{PAH}$ standard solution from the online HPLC fractionation system: (A) full-scale chromatogram, (B) enlarged chromatogram depicting fractionation points. Conditions: two PYE columns $(150 \times 4.6 \mathrm{~mm}, 5 \mu \mathrm{m})$, hexane $100 \%$, flow rate $0.8 \mathrm{~mL} / \mathrm{min}$, column temperature at $30^{\circ} \mathrm{C}$, UV detection at $254 \mathrm{~nm}$, UV detector sensitivity of 0.02 AUFS. AU: absorbance units, F: fraction, W: waste.

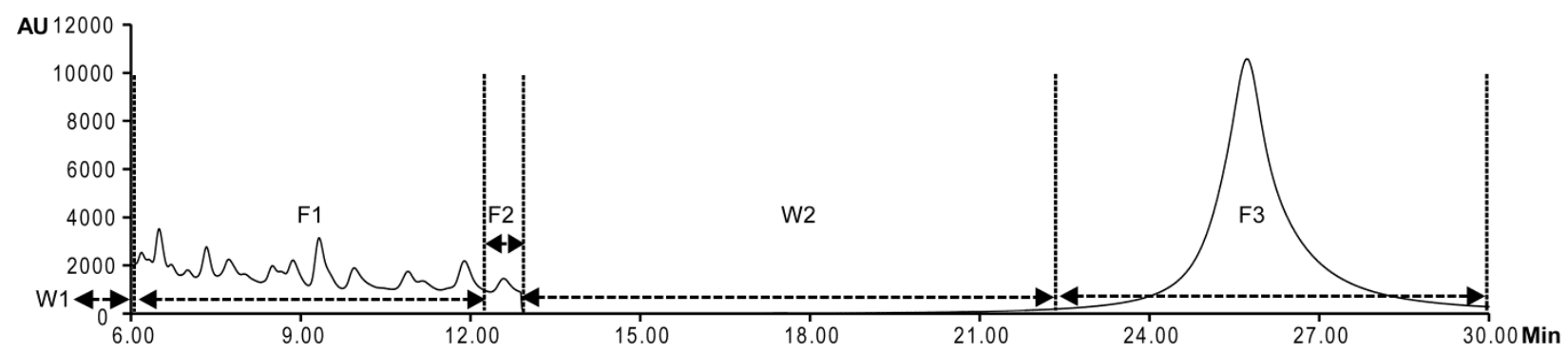

Fig. 3. HPLC/UV chromatogram of an injection of a Stockholm air PM extract on the B $[a]$ P-specific online HPLC fractionation system. Instrumental conditions are described in Fig. 2. 


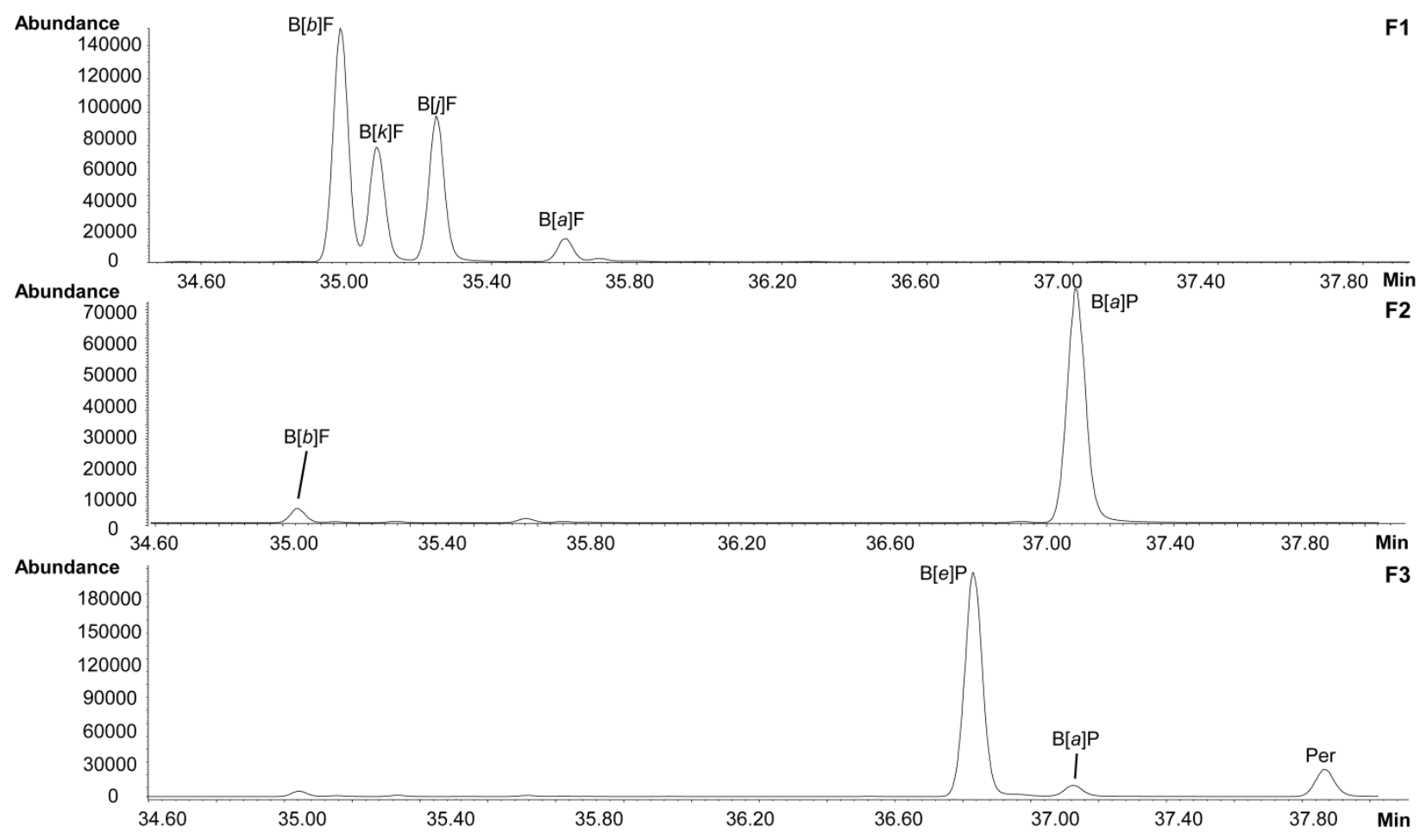

Fig. 4. GC/MS extracted ion chromatograms $(\mathrm{m} / \mathrm{z}, 252)$ of the fractions generated from an injection of a Stockholm air PM extract on the $\mathrm{B}[a] \mathrm{P}$-specific online HPLC fractionation system. 


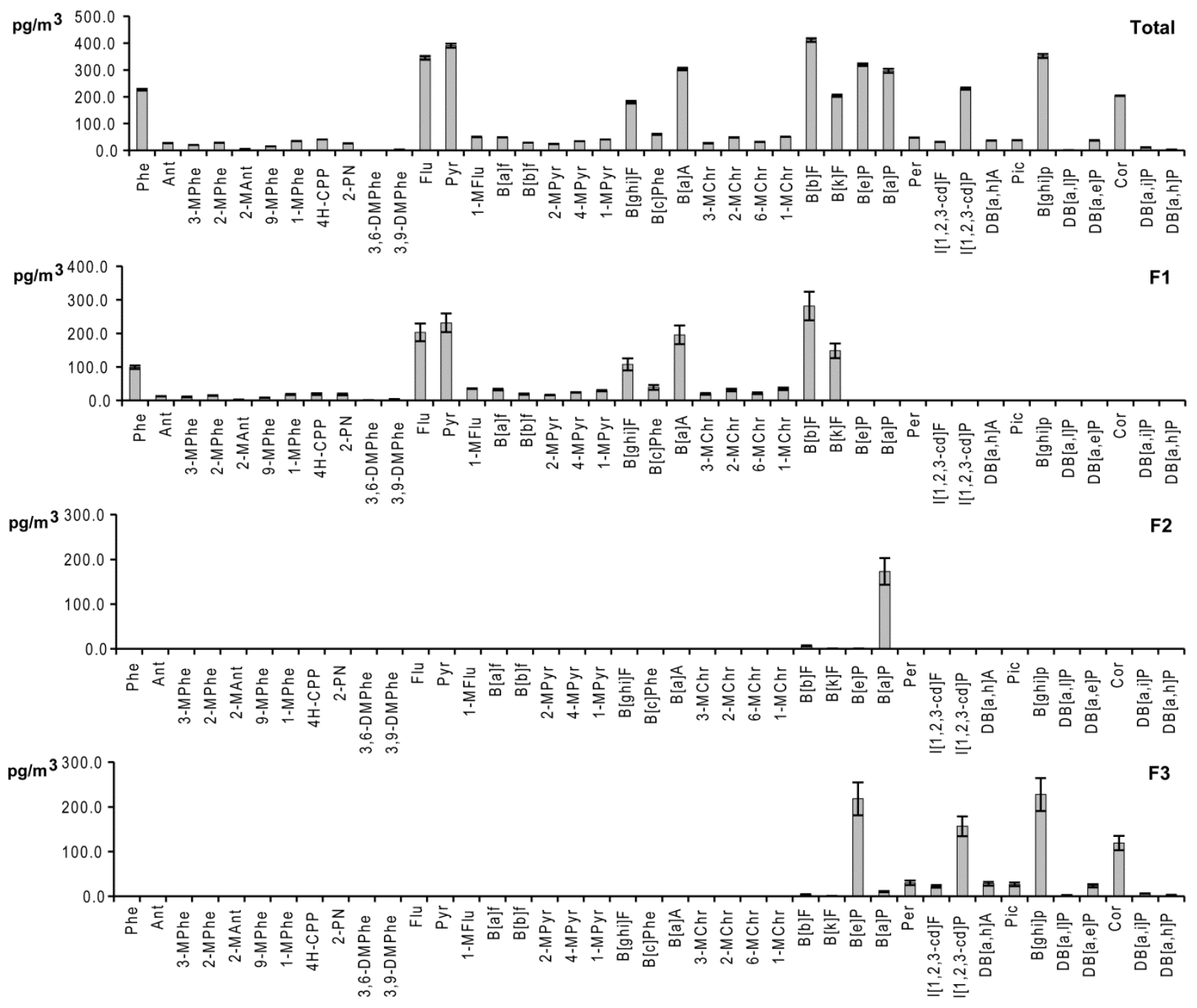

Fig. 5. PAH concentrations determined in a Stockholm air PM extract and in the fractions collected from the $\mathrm{B}[a] \mathrm{P}$ specific online HPLC fractionation system. Error bars show one standard deviation from the mean value $(n=3)$. Compound abbreviations are shown in Table S1.

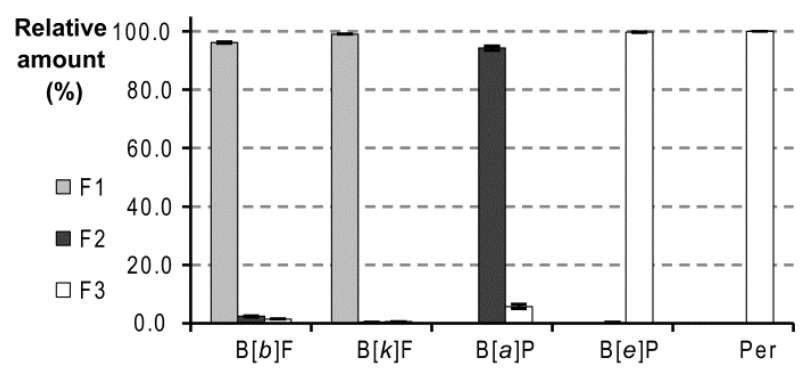

Fig. 6. Relative abundance of $252 \mathrm{Da}$ molecular weight PAHs in the fractions generated by the $\mathrm{B}[a] \mathrm{P}$-specific online HPLC fractionation system. Error bars show one standard deviation from the mean value $(n=3)$. 


\section{Supplementary data}

2 Benzo[a]pyrene-specific online HPLC fractionation of air particulate extracts - A tool for

3 evaluating biological interactions

4 Hwanmi Lim $^{\mathrm{a}}$, Christoffer Bergvall ${ }^{\mathrm{a}}$, Ian Jarvis ${ }^{\mathrm{b}}$, Åse Mattsson ${ }^{\mathrm{b}}$, Kristian Dreij ${ }^{\mathrm{b}}$, Ulla Stenius ${ }^{\mathrm{b}}$, Roger Westerholm ${ }^{\mathrm{a}, *}$

5 a Department of Analytical Chemistry, Stockholm University, Svante Arrhenius väg 16 SE-106 91 Stockholm, 6 Sweden

$7 \quad{ }^{\mathrm{b}}$ Institute of Environmental Medicine, Karonlinska Institutet, Box 210, SE-171 77 Stockholm, Sweden

9 Contents

10 S-1. List of PAH standards and internal standards

11 S-2. Schematic illustration of the B $[a] \mathrm{P}$-specific online HPLC fractionation system

12 S-3. Valve positions during a run on the $\mathrm{B}[a] \mathrm{P}$-specific online HPLC fractionation system

13 S-4. GC/MS chromatograms of Stockholm air PM extract from the B $[a]$ P-specific online HPLC fractionation system

14 S-5. GC/MS chromatograms of blank and hexane injections on the $\mathrm{B}[a] \mathrm{P}$-specific online HPLC fractionation system

15 S-6. GC/MS full scan mass spectra of the system peaks from the $\mathrm{B}[a] \mathrm{P}$-specific online HPLC fractionation system

16 S-7. Biological tests of eluates from the $\mathrm{B}[a] \mathrm{P}$-specific online HPLC fractionation system

17 S-8. GC/MS full scan analysis of blank, non-fractionated and fractionated samples

18 S-9. PAH concentrations in Stockholm air PM sample 
20 Table S1. List of PAH standards and surrogate internal standards with abbreviation, CAS Registry number, supplier, purity, molecular formula (M.f.) and 21 molecular weight (M.w. in $\mathrm{g} / \mathrm{mol}$ )

\begin{tabular}{|c|c|c|c|c|c|c|}
\hline Name & Abbreviation & CAS Registry No. & Supplier & $\begin{array}{l}\text { Purity } \\
(\%)\end{array}$ & M.f. & M.w. \\
\hline Phenanthrene & Phe & $85-01-8$ & Merck, Germany & 98.7 & $\mathrm{C}_{14} \mathrm{H}_{10}$ & 178.23 \\
\hline Anthracene & Ant & $120-12-7$ & Sigma-Aldrich, St. Louis, MO, USA & 99.6 & $\mathrm{C}_{14} \mathrm{H}_{10}$ & 178.23 \\
\hline 3-Methylphenanthrene & 3-MPhe & $832-71-3$ & Larodan Fine Chemicals AB, Sweden & 99.9 & $\mathrm{C}_{15} \mathrm{H}_{12}$ & 192.26 \\
\hline 2-Methylphenanthrene & 2-MPhe & $2531-84-2$ & Sigma-Aldrich, St. Louis, MO, USA & 93.8 & $\mathrm{C}_{15} \mathrm{H}_{12}$ & 192.26 \\
\hline 2-Methylanthracene & 2-MAnt & $613-12-7$ & Koch-Light Laboratories, UK & 100 & $\mathrm{C}_{15} \mathrm{H}_{12}$ & 192.26 \\
\hline 9-Methylphenanthrene & 9-MPhe & $883-20-5$ & Chiron AS, Trondheim, Norway & 100 & $\mathrm{C}_{15} \mathrm{H}_{12}$ & 192.26 \\
\hline 1-Methylphenanthrene & 1-MPhe & $832-69-9$ & Larodan Fine Chemicals AB, Sweden & 98.8 & $\mathrm{C}_{15} \mathrm{H}_{12}$ & 192.26 \\
\hline 4H-Cyclopenta[def]phenanthrene & $4 H$-СРP & $203-64-5$ & Sigma-Aldrich, St. Louis, MO, USA & 99.1 & $\mathrm{C}_{15} \mathrm{H}_{10}$ & 190.24 \\
\hline 2-Phenylnaphthalene & 2-PN & $612-94-2$ & EGA-Chemie, Steinheim, Germany & 94.2 & $\mathrm{C}_{16} \mathrm{H}_{12}$ & 204.27 \\
\hline 3,6-Dimethylphenanthrene & 3,6-DMPhe & $1576-67-6$ & Larodan Fine Chemicals AB, Sweden & 96.1 & $\mathrm{C}_{16} \mathrm{H}_{14}$ & 206.28 \\
\hline 3,9-Dimethylphenanthrene & 3,9-DMPhe & $66291-32-5$ & Chiron AS, Trondheim, Norway & 99.7 & $\mathrm{C}_{16} \mathrm{H}_{14}$ & 206.28 \\
\hline
\end{tabular}




\begin{tabular}{|c|c|c|c|c|c|c|}
\hline Fluoranthene & Flu & $206-44-0$ & Sigma-Aldrich, St. Louis, MO, USA & 97.2 & $\mathrm{C}_{16} \mathrm{H}_{10}$ & 202.25 \\
\hline Pyrene & Pyr & $129-00-0$ & Janssen Chimica, Belgium & 97.6 & $\mathrm{C}_{16} \mathrm{H}_{10}$ & 202.25 \\
\hline 1-Methylfluoranthene & 1-MFlu & $25889-60-5$ & Chiron AS, Trondheim, Norway & 99.7 & $\mathrm{C}_{17} \mathrm{H}_{12}$ & 216.28 \\
\hline Benzo $[a]$ fluorene & $\mathrm{B}[a] \mathrm{f}$ & $238-84-6$ & Chiron AS, Trondheim, Norway & 98.8 & $\mathrm{C}_{17} \mathrm{H}_{12}$ & 216.28 \\
\hline Benzo $[b]$ fluorene & $\mathrm{B}[b] \mathrm{f}$ & $243-17-4$ & Sigma-Aldrich, St. Louis, MO, USA & 99.1 & $\mathrm{C}_{17} \mathrm{H}_{12}$ & 216.28 \\
\hline 2-Methylpyrene & 2-MPyr & $3442-78-2$ & Chiron AS, Trondheim, Norway & 98.3 & $\mathrm{C}_{17} \mathrm{H}_{12}$ & 216.28 \\
\hline 4-Methylpyrene & 4-MPyr & $3353-12-6$ & Chiron AS, Trondheim, Norway & 99.6 & $\mathrm{C}_{17} \mathrm{H}_{12}$ & 216.28 \\
\hline 1-Methylpyrene & 1-MPyr & $2381-21-7$ & Larodan Fine Chemicals AB, Sweden & 99.1 & $\mathrm{C}_{17} \mathrm{H}_{12}$ & 216.28 \\
\hline Benzo[ghi]fluoranthene & $\mathrm{B}[g h i] \mathrm{F}$ & $203-12-3$ & Larodan Fine Chemicals AB, Sweden & 99.5 & $\mathrm{C}_{18} \mathrm{H}_{10}$ & 226.27 \\
\hline Benzo $[c]$ phenanthrene & $\mathrm{B}[c] \mathrm{Phe}$ & $195-19-7$ & Chiron AS, Trondheim, Norway & 99.5 & $\mathrm{C}_{18} \mathrm{H}_{12}$ & 228.29 \\
\hline Benz $[a]$ anthracene & $\mathrm{B}[a] \mathrm{A}$ & $56-55-3$ & Fluka AG, Switzerland & 98.4 & $\mathrm{C}_{18} \mathrm{H}_{12}$ & 228.29 \\
\hline 3-Methylchrysene & 3-MChr & $3351-31-3$ & Chiron AS, Trondheim, Norway & 99.1 & $\mathrm{C}_{19} \mathrm{H}_{14}$ & 242.31 \\
\hline 2-Methylchrysene & 2-MChr & $3351-32-4$ & Chiron AS, Trondheim, Norway & 99.7 & $\mathrm{C}_{19} \mathrm{H}_{14}$ & 242.31 \\
\hline 6-Methylchrysene & 6-MChr & $1705-85-7$ & Chiron AS, Trondheim, Norway & 100 & $\mathrm{C}_{19} \mathrm{H}_{14}$ & 242.31 \\
\hline 1-Methylchrysene & 1-MChr & $3351-28-8$ & Chiron AS, Trondheim, Norway & 99.3 & $\mathrm{C}_{19} \mathrm{H}_{14}$ & 242.31 \\
\hline Benzo $[b]$ fluoranthene & $\mathrm{B}[b] \mathrm{F}$ & $205-99-2$ & Chem Service, West Chester, PA, USA & 100 & $\mathrm{C}_{20} \mathrm{H}_{12}$ & 252.31 \\
\hline
\end{tabular}




\begin{tabular}{|c|c|c|c|c|c|c|}
\hline Benzo $[k]$ fluoranthene & $\mathrm{B}[k] \mathrm{F}$ & $207-08-9$ & Chem Service, West Chester, PA, USA & 98.3 & $\mathrm{C}_{20} \mathrm{H}_{12}$ & 252.31 \\
\hline Benzo $[e]$ pyrene & $\mathrm{B}[e] \mathrm{P}$ & $192-97-2$ & Sigma-Aldrich, St. Louis, MO, USA & 99.7 & $\mathrm{C}_{20} \mathrm{H}_{12}$ & 252.31 \\
\hline Benzo $[a]$ pyrene & $\mathrm{B}[a] \mathrm{P}$ & $50-32-8$ & Sigma-Aldrich, St. Louis, MO, USA & 97.6 & $\mathrm{C}_{20} \mathrm{H}_{12}$ & 252.31 \\
\hline Perylene & Per & $198-55-0$ & Sigma-Aldrich, St. Louis, MO, USA & 99.5 & $\mathrm{C}_{20} \mathrm{H}_{12}$ & 252.31 \\
\hline Indeno[1,2,3-cd] fluoranthene & $\mathrm{I}[1,2,3-c d] \mathrm{F}$ & $193-43-1$ & $\begin{array}{l}\text { Radiant Dyes, Wermelskirchen, } \\
\text { Germany }\end{array}$ & 98.4 & $\mathrm{C}_{22} \mathrm{H}_{12}$ & 276.33 \\
\hline Indeno $[1,2,3-c d]$ pyrene & $\mathrm{I}[1,2,3-c d] \mathrm{P}$ & $193-39-5$ & $\begin{array}{l}\text { AccuStandard Inc., New Haven, CT, } \\
\text { USA }\end{array}$ & 99.8 & $\mathrm{C}_{22} \mathrm{H}_{12}$ & 276.33 \\
\hline $\operatorname{Dibenz}[a, h]$ anthracene & $\mathrm{DB}[a, h] \mathrm{A}$ & $53-70-3$ & Fluka AG, Switzerland & 99.4 & $\mathrm{C}_{22} \mathrm{H}_{14}$ & 278.35 \\
\hline Picene & Pic & $213-46-7$ & Larodan Fine Chemicals AB, Sweden & 96.1 & $\mathrm{C}_{22} \mathrm{H}_{14}$ & 278.35 \\
\hline Benzo[ghi]perylene & $\mathrm{B}[g h i] \mathrm{p}$ & $191-24-2$ & Janssen Chimica, Belgium & 98.8 & $\mathrm{C}_{22} \mathrm{H}_{12}$ & 276.33 \\
\hline Dibenzo $[a, l]$ pyrene & $\mathrm{DB}[a, l] \mathrm{P}$ & $191-30-0$ & $\begin{array}{l}\text { AccuStandard Inc., New Haven, CT, } \\
\text { USA }\end{array}$ & 96 & $\mathrm{C}_{24} \mathrm{H}_{14}$ & 302.37 \\
\hline Dibenzo[a,e]pyrene & $\mathrm{DB}[a, e] \mathrm{P}$ & $192-65-4$ & LGC Promochem, Sweden & 98 & $\mathrm{C}_{24} \mathrm{H}_{14}$ & 302.37 \\
\hline Coronene & Cor & $191-07-1$ & $\begin{array}{l}\text { Radiant Dyes, Wermelskirchen, } \\
\text { Germany }\end{array}$ & 100 & $\mathrm{C}_{24} \mathrm{H}_{12}$ & 300.35 \\
\hline Dibenzo[a,i]pyrene & $\mathrm{DB}[a, i] \mathrm{P}$ & $189-55-9$ & Sigma-Aldrich, St. Louis, MO, USA & 96.4 & $\mathrm{C}_{24} \mathrm{H}_{14}$ & 302.37 \\
\hline
\end{tabular}




\begin{tabular}{|c|c|c|c|c|c|c|}
\hline Dibenzo $[a, h]$ pyrene & $\mathrm{DB}[a, h] \mathrm{P}$ & $189-64-0$ & Koch-Light Laboratories, UK & 100 & $\mathrm{C}_{24} \mathrm{H}_{14}$ & 302.37 \\
\hline \multirow[t]{2}{*}{ Phenanthrene- $\mathrm{D}_{10}$} & Phe- $\mathrm{D}_{10}$ & $1517-22-2$ & Chiron AS, Trondheim, Norway ${ }^{\mathrm{a}}$, & $\begin{array}{l}99.3^{\mathrm{a}} \\
97.2^{\mathrm{b}}\end{array}$ & $\mathrm{C}_{14} \mathrm{D}_{10}$ & 188.29 \\
\hline & & & Larodan Fine Chemicals AB, Sweden ${ }^{\mathrm{b}}$ & & & \\
\hline \multirow[t]{3}{*}{ Pyrene- $\mathrm{D}_{10}$} & Pyr- $D_{10}$ & $1718-52-1$ & Chiron AS, Trondheim, Norway ${ }^{\mathrm{a}}$, & $99.8^{\mathrm{a}}$, & $\mathrm{C}_{16} \mathrm{D}_{10}$ & 212.31 \\
\hline & & & & $95.7^{\mathrm{b}}$ & & \\
\hline & & & Larodan Fine Chemicals AB, Sweden ${ }^{\mathrm{b}}$ & & & \\
\hline $\operatorname{Benz}[a]$ anthracene- $\mathrm{D}_{12}$ & $\mathrm{~B}[a] \mathrm{A}-\mathrm{D}_{12}$ & $1718-53-2$ & Chiron AS, Trondheim, Norway & 98.6 & $\mathrm{C}_{18} \mathrm{D}_{12}$ & 240.36 \\
\hline \multirow[t]{3}{*}{ Benzo $[a]$ pyrene- $\mathrm{D}_{12}$} & $\mathrm{~B}[a] \mathrm{P}-\mathrm{D}_{12}$ & $63466-71-7$ & Chiron AS, Trondheim, Norway ${ }^{\mathrm{a}}$, & $98.7^{\mathrm{a}}$, & $\mathrm{C}_{20} \mathrm{D}_{12}$ & 264.38 \\
\hline & & & & $98.1^{\mathrm{b}}$ & & \\
\hline & & & Larodan Fine Chemicals AB, Sweden ${ }^{\mathrm{b}}$ & & & \\
\hline Benzo $\left[\right.$ ghi]perylene- $\mathrm{D}_{12}$ & $\mathrm{B}[g h i] \mathrm{p}-\mathrm{D}_{12}$ & 93951-66-7 & Chiron AS, Trondheim, Norway & 99.6 & $\mathrm{C}_{22} \mathrm{D}_{12}$ & 288.4 \\
\hline Dibenzo $[a, i]$ pyrene- $\mathrm{D}_{14}$ & $\mathrm{DB}[a, i] \mathrm{P}-\mathrm{D}_{14}$ & 158776-07-9 & LGC Promochem, Sweden & 98 & $\mathrm{C}_{24} \mathrm{D}_{14}$ & 316.45 \\
\hline $\left.\operatorname{Benzo}_{a} a\right]_{\text {fluoranthene }}{ }^{\mathrm{c}}$ & $\mathrm{B}[a] \mathrm{F}$ & 203-33-8 & Gift from NIST & - & $\mathrm{C}_{20} \mathrm{H}_{12}$ & 252.31 \\
\hline Benzo[j]fluoranthene $^{c}$ & $\mathrm{~B}[j] \mathrm{F}$ & $205-82-3$ & Larodan Fine Chemicals AB, Sweden & 100 & $\mathrm{C}_{20} \mathrm{H}_{12}$ & 252.31 \\
\hline
\end{tabular}

$22{ }^{a}$ Surrogate internal standard working solution used for sample preparation

$23{ }^{\mathrm{b}}$ Surrogate internal standard used for PAH calibration standard preparation

$24{ }^{\mathrm{c}}$ Not used for quantitation 


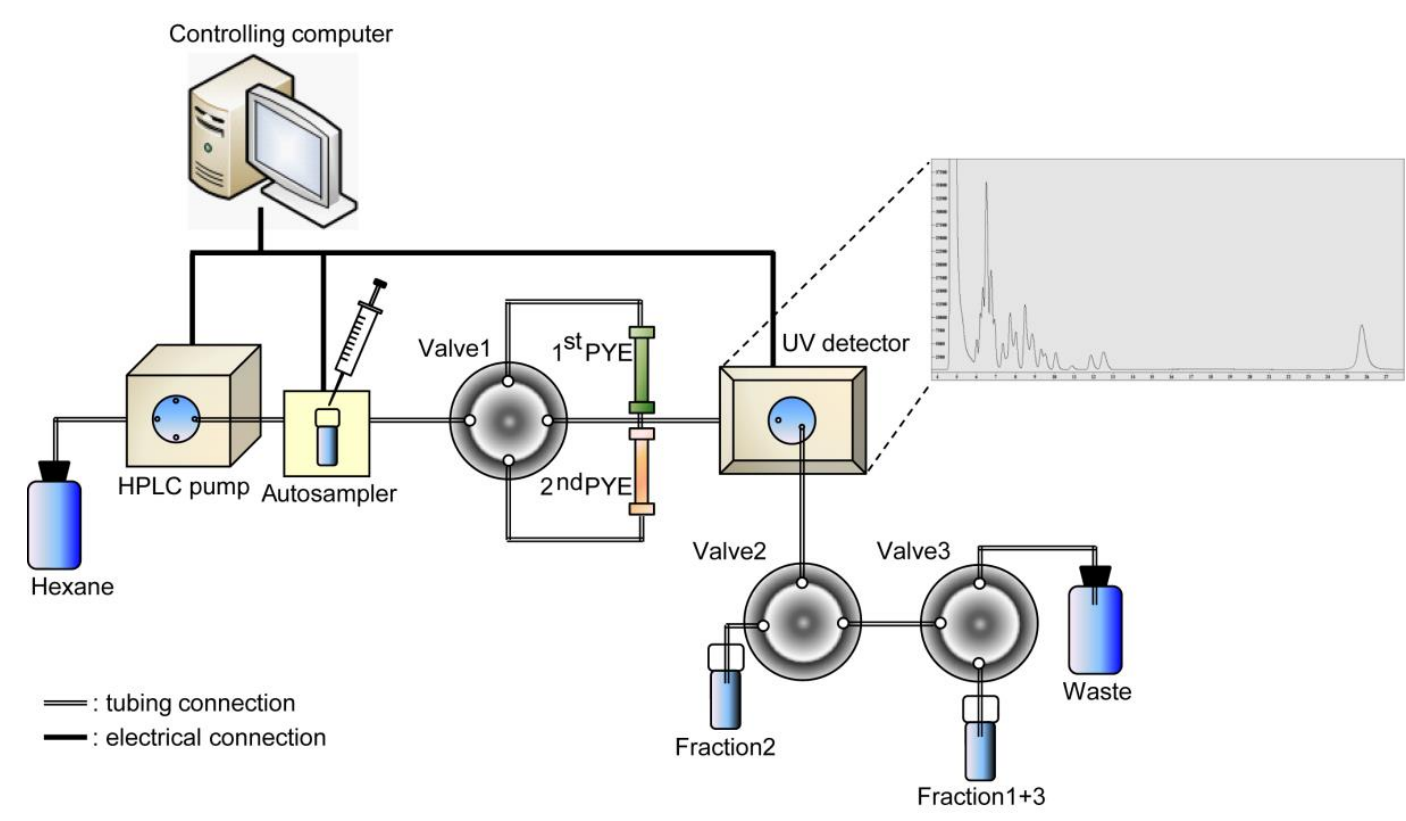

27 Fig. S1. Scheme of the online HPLC fractionation system. 
A
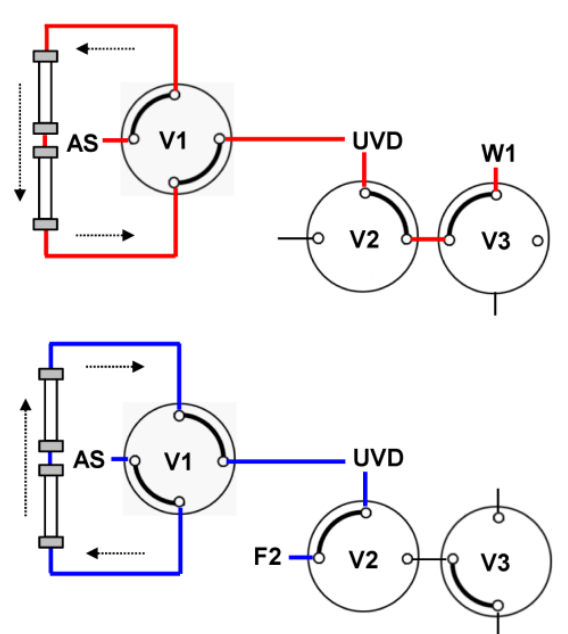

B

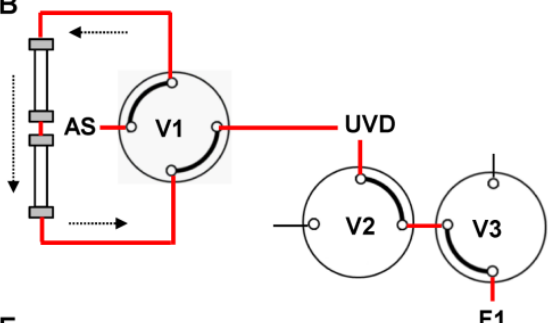

E

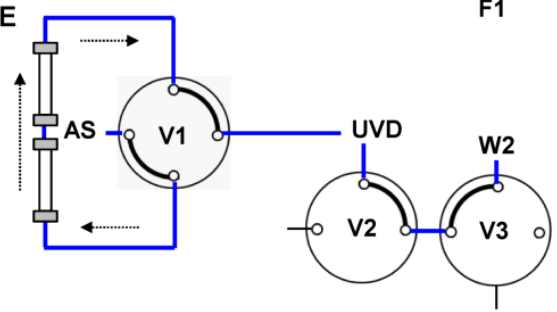

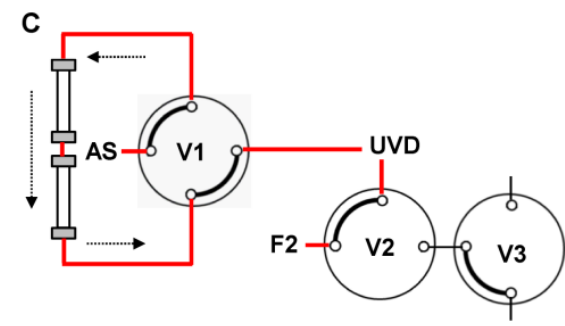

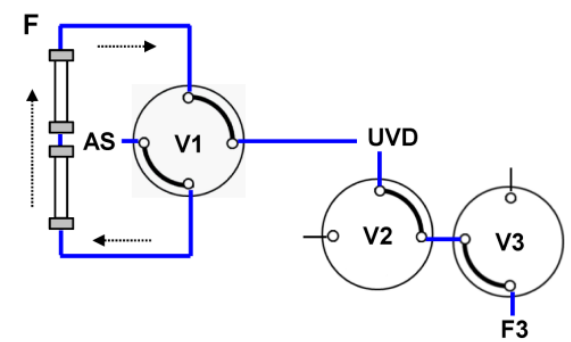

30 Fig. S2. Scheme illustrating the valve positions and flow paths during a run of the B $[a]$ P-specific online HPLC fractionation system: (A)-(C) and (D)-(F) indicate column flow before and after backflush, respectively. AS: autosampler, V: two position-switching valve, UVD: UV detector, F: fraction, W: waste. 
32 Table S2. Valve positions during the different steps of a run on the $\mathrm{B}[a] \mathrm{P}$-specific online HPLC fractionation system

\begin{tabular}{lllll}
\hline Time (min) & V1 & V2 & V3 & Shown in F \\
\hline 0.00 & 0 & 0 & 0 & Fig. S2, A \\
$6.05^{\mathrm{a}}$ & 0 & 0 & 1 & Fig. S2, B \\
$12.35^{\mathrm{b}}$ & 0 & 1 & 1 & Fig. S2, C \\
$12.85^{\mathrm{c}}$ & 1 & 1 & 1 & Fig. S2, D \\
$13.05^{\mathrm{b}}$ & 1 & 0 & 0 & Fig. S2, $\mathrm{C}$ \\
$22.20^{\mathrm{a}}$ & 1 & 0 & 1 & Fig. S2, F \\
$29.20^{\mathrm{a}}$ & 1 & 0 & 0 & Fig. S2, A \\
30.00 & 0 & 0 & 0 & Fig. S2, A
\end{tabular}

33 a Adjusted time corrected by adding 0.2 minutes from the observed retention time due to the dead volume after the UV detector

$34{ }^{\mathrm{b}}$ Adjusted backflush time corrected by subtracting 0.05 minutes from the observed retention time due to the time lag of the switching valve

$35{ }^{\mathrm{c}}$ Adjusted time corrected by adding 0.15 minutes from the observed retention time due to the dead volume after the UV detector 


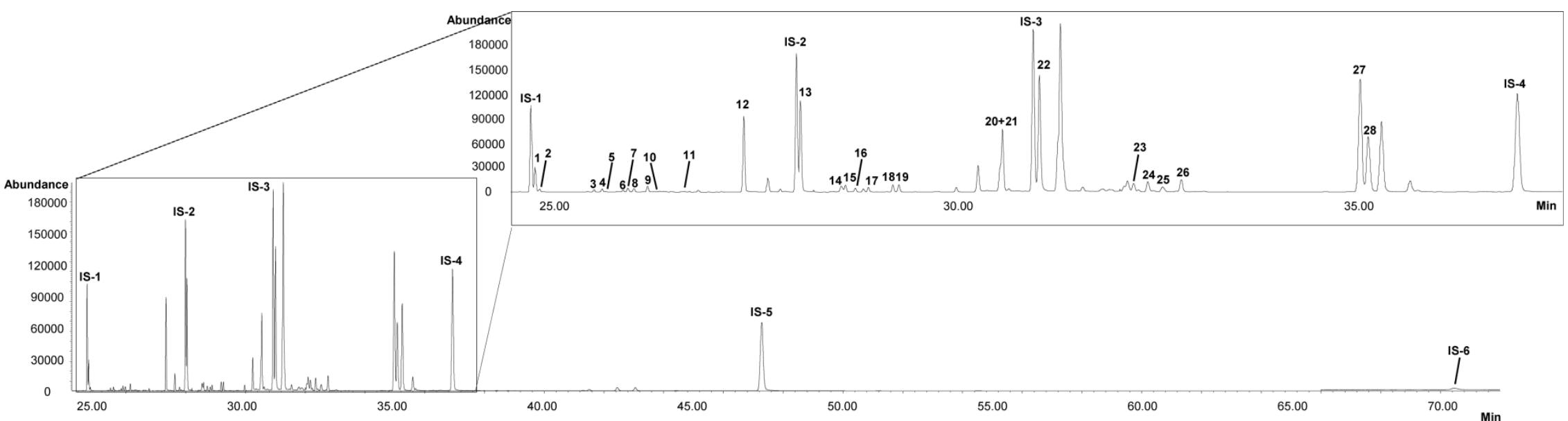

38 Figure S3. GC/MS chromatogram obtained in SIM mode of fraction F1 from an injection of a Stockholm air PM extract on the B $[a] \mathrm{P}-\mathrm{specific}$ online HPLC 39 fractionation system. 1: Phe, 2: Ant, 3: 3-MPhe, 4: 2-MPhe, 5: 2-MAnt, 6: 9-MPhe, 7: 1-MPhe, 8: 4H-CPP, 9: 2-PN, 10: 3,6-DMPhe, 11: 3,9-DMPhe, 12: Flu,

40 13: Pyr, 14: 1-MFlu, 15: B[a]f, 16: B[b]f, 17: 2-MPyr, 18: 4-MPyr, 19: 1-MPyr, 20: B[ghi]F, 21: B[c]Phe, 22: B[a]A, 23: 3-MChr, 24: 2-MChr, 25: 6-MChr, 26:

41 1-MChr, 27: B[b]F, 28: B[k]F, IS-1: Phe-D ${ }_{10}$, IS-2: Pyr-D 10 , IS-3: B[a]A-D ${ }_{12}$, IS-4: B[a]P-D 12 , IS-5: B $[g h i] p-D_{12}$, IS-6: DB $[a, i]$ P-D 14. 


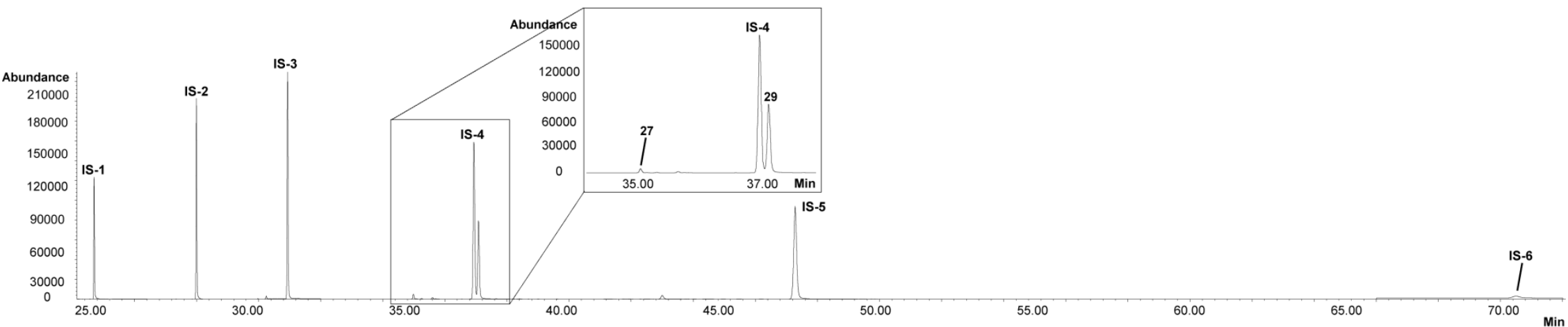

43 Figure S4. GC/MS chromatogram obtained in SIM mode of fraction F2 from an injection of a Stockholm air PM extract on the B $[a] \mathrm{P}$-specific online HPLC

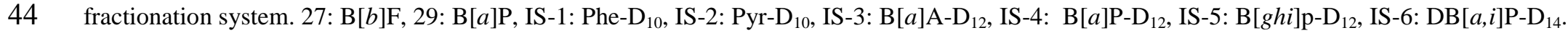

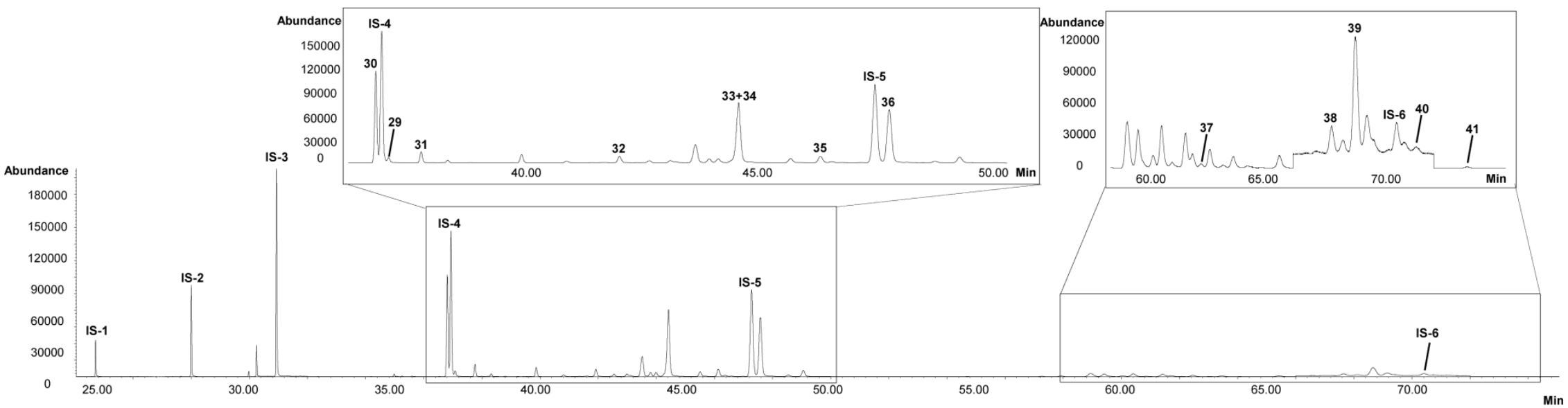

47 Figure S5. GC/MS chromatogram obtained in SIM mode of fraction F3 from an injection of a Stockholm air PM extract on the B $[a] \mathrm{P}-$ specific online HPLC

48 fractionation system. 30: $\mathrm{B}[e] \mathrm{P}, 29: \mathrm{B}[a] \mathrm{P}, 31$ : Per, 32: $\mathrm{I}[1,2,3-c d] \mathrm{F}, 33: \mathrm{I}[1,2,3-c d] \mathrm{P}, 34: \mathrm{DB}[a, h] \mathrm{A}, 35:$ Pic, 36: B[ghi]p, 37: DB $[a, l] \mathrm{P}, 38: \mathrm{DB}[a, e] \mathrm{P}, 39: \mathrm{Cor}$,

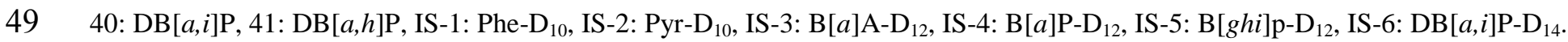




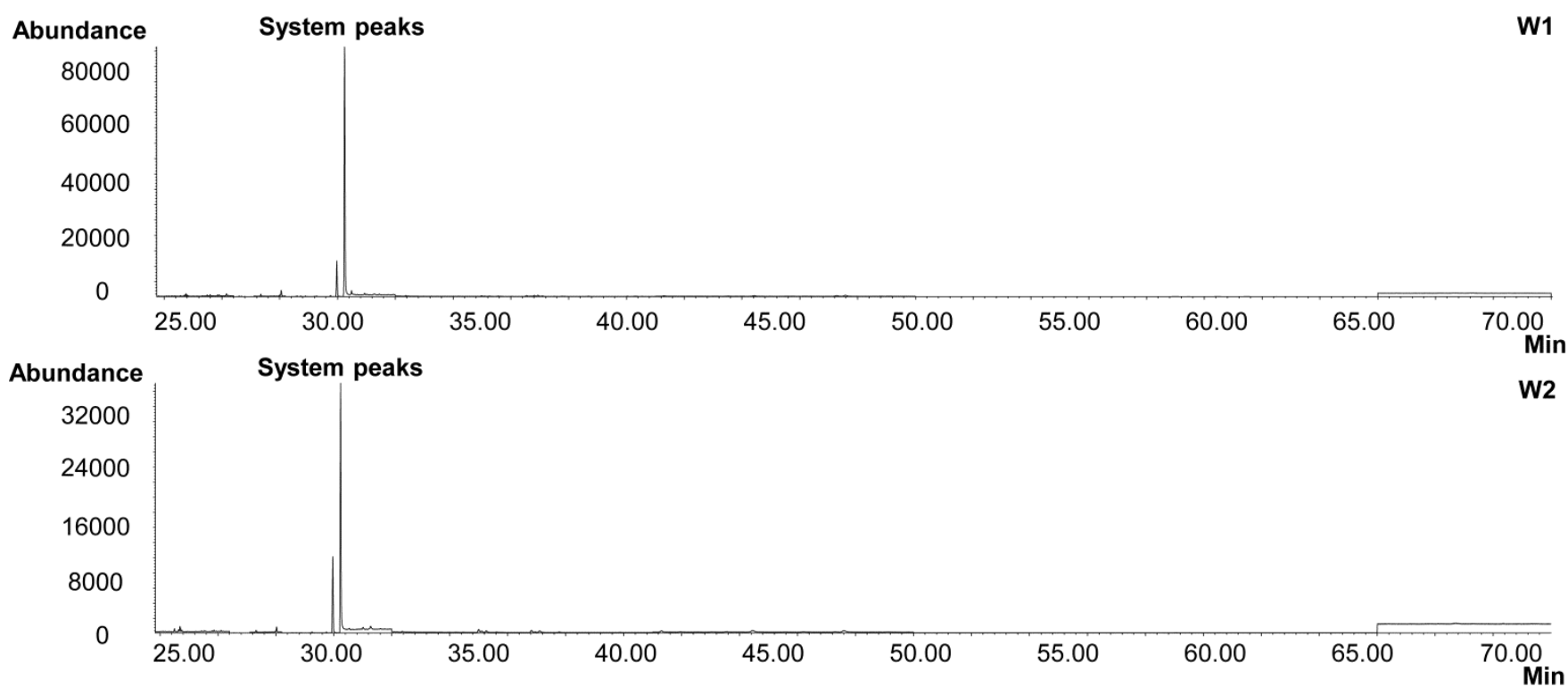

51 Figure S6. GC/MS chromatogram obtained in SIM mode of waste W1 and W2 from an injection of a Stockholm air PM extract on the B $[a] \mathrm{P}$-specific online 52 HPLC fractionation system. 
53 S-5. GC/MS chromatograms of blank and hexane injections on the B[a]P-specific online HPLC fractionation system

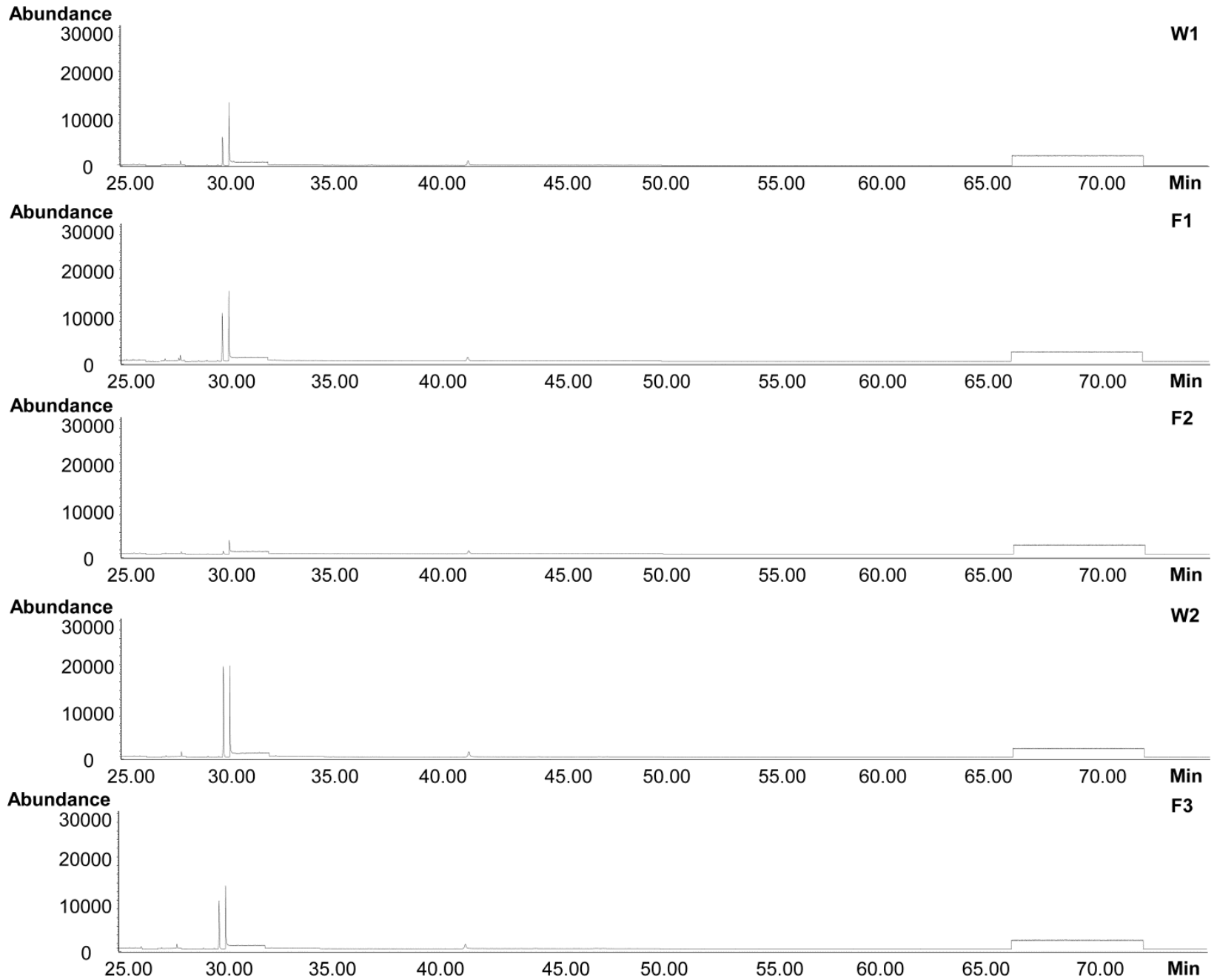

55 Figure S7. GC/MS chromatograms obtained in SIM mode of fractions F1, F2, F3, W1 and W2 from a blank 56 injection on the $\mathrm{B}[a] \mathrm{P}$-specific online HPLC fractionation system. 


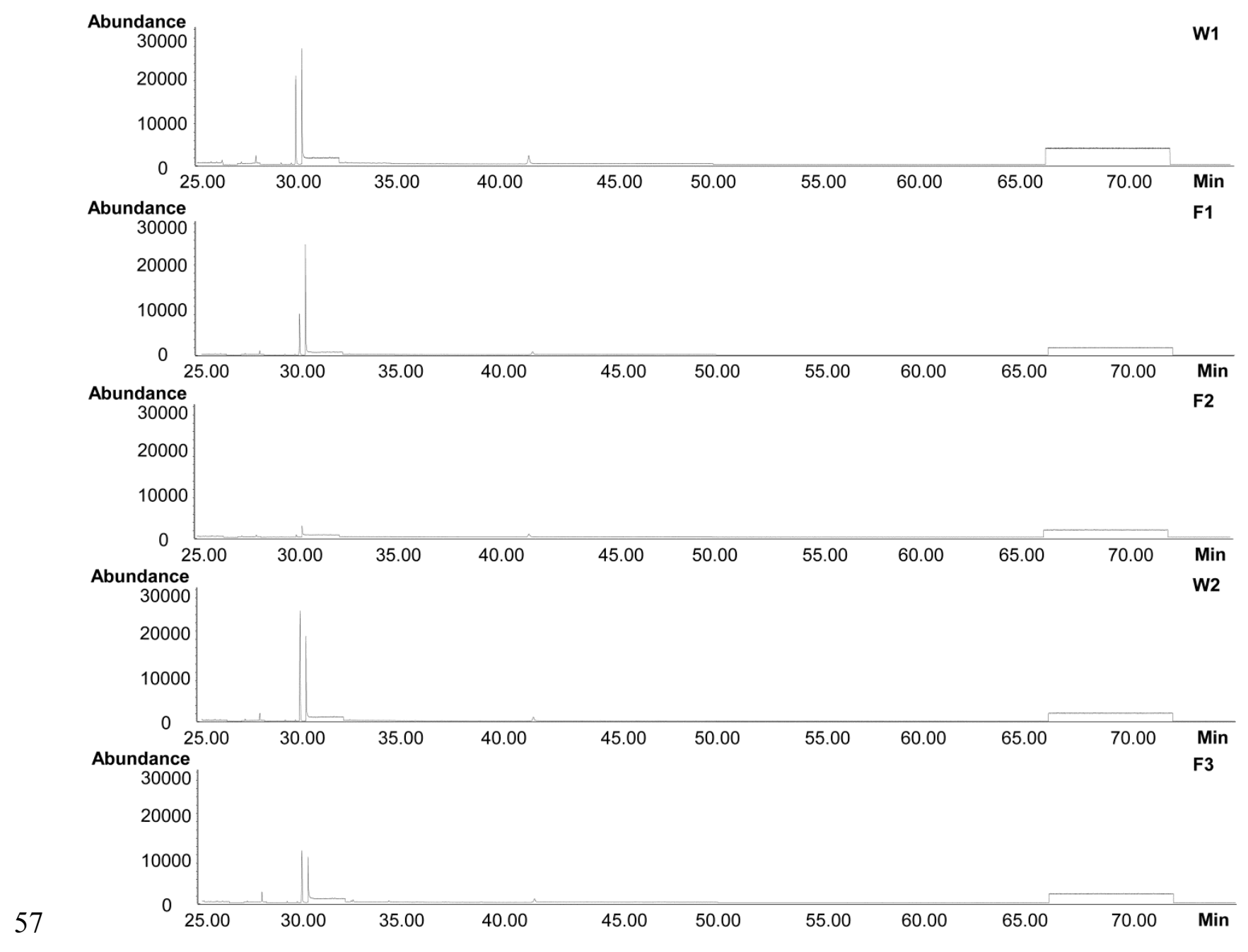

58 Figure S8. GC/MS chromatograms obtained in SIM mode of fractions F1, F2, F3, W1 and W2 from a hexane 59 injection on the $\mathrm{B}[a] \mathrm{P}$-specific online HPLC fractionation system. 


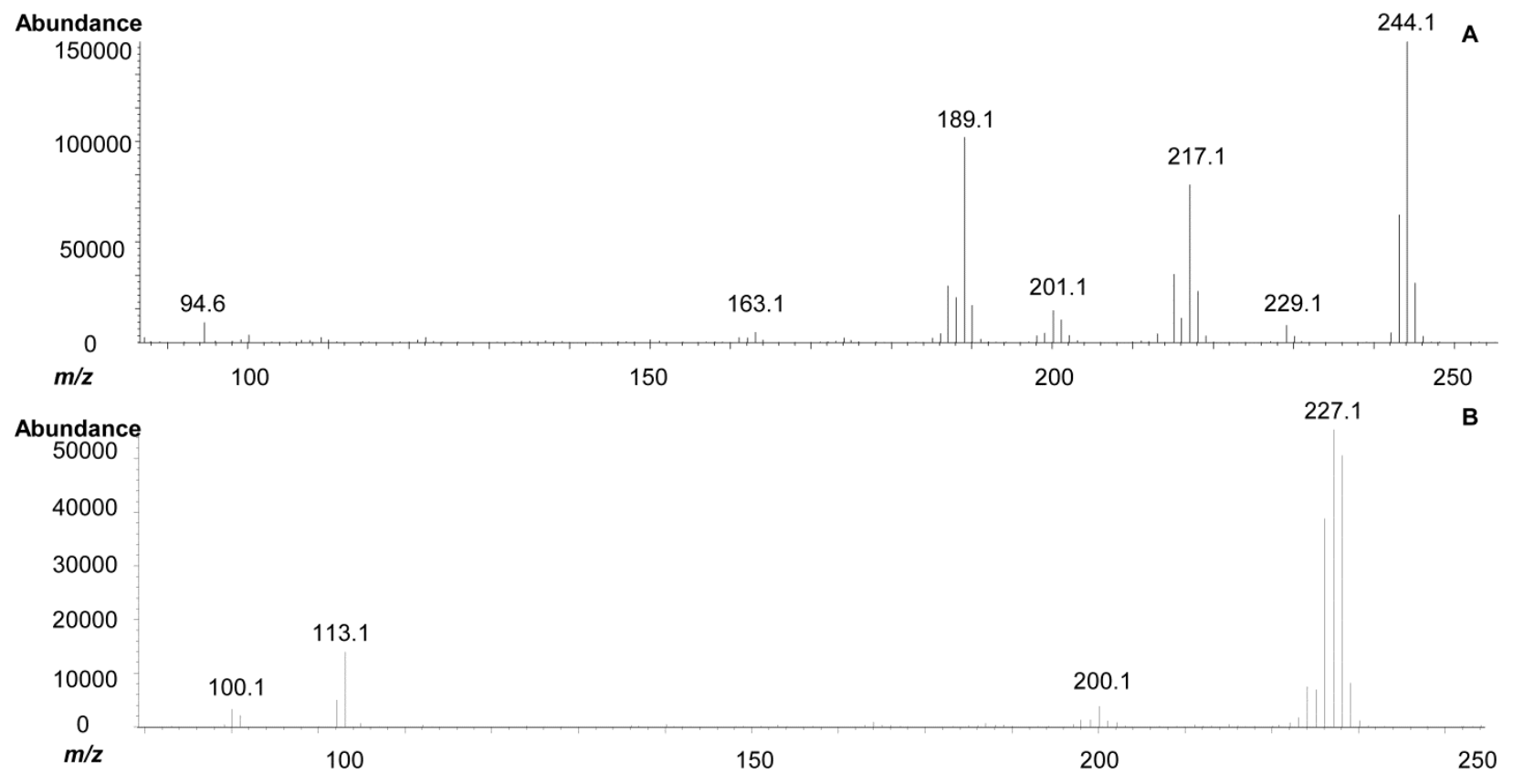

62 Figure S9. Full scan mass spectra of system peaks at (A) 29.88 and (B) $30.15 \mathrm{~min}$.

63 Table S3. Analytical method for the GC/MS analysis

\begin{tabular}{lll}
\hline Name & Condition & \\
\hline GC & Agilent $6890 \mathrm{~N}$ (Agilent Technologies, Palo Alto, CA, USA) \\
& Injection & $1 \mu \mathrm{L}$, splitless at $300^{\circ} \mathrm{C}$ \\
& Carrier gas & $\mathrm{He}$ \\
& Column & $\mathrm{J}$ W DB-5ms $30 \mathrm{~m} \times 0.25 \mathrm{~mm}, 0.25 \mu \mathrm{m}$ phase \\
& Oven & $60{ }^{\circ} \mathrm{C}$ for $2 \mathrm{~min}, 20{ }^{\circ} \mathrm{C} / \mathrm{min}$ to $200{ }^{\circ} \mathrm{C}, 10{ }^{\circ} \mathrm{C} / \mathrm{min}$ to $300{ }^{\circ} \mathrm{C}$ for $10 \mathrm{~min}$ \\
& & \\
\hline MS & MSD $5975 \mathrm{C}($ Agilent Technologies, Palo Alto, CA, USA)
\end{tabular}

Electron ionization at $70 \mathrm{eV}$, full scan mode $(\mathrm{m} / \mathrm{z}, 50-450)$, solvent delay $6.00 \mathrm{~min}$, quadrupole at $150{ }^{\circ} \mathrm{C}$, ion source at $300^{\circ} \mathrm{C}$ 


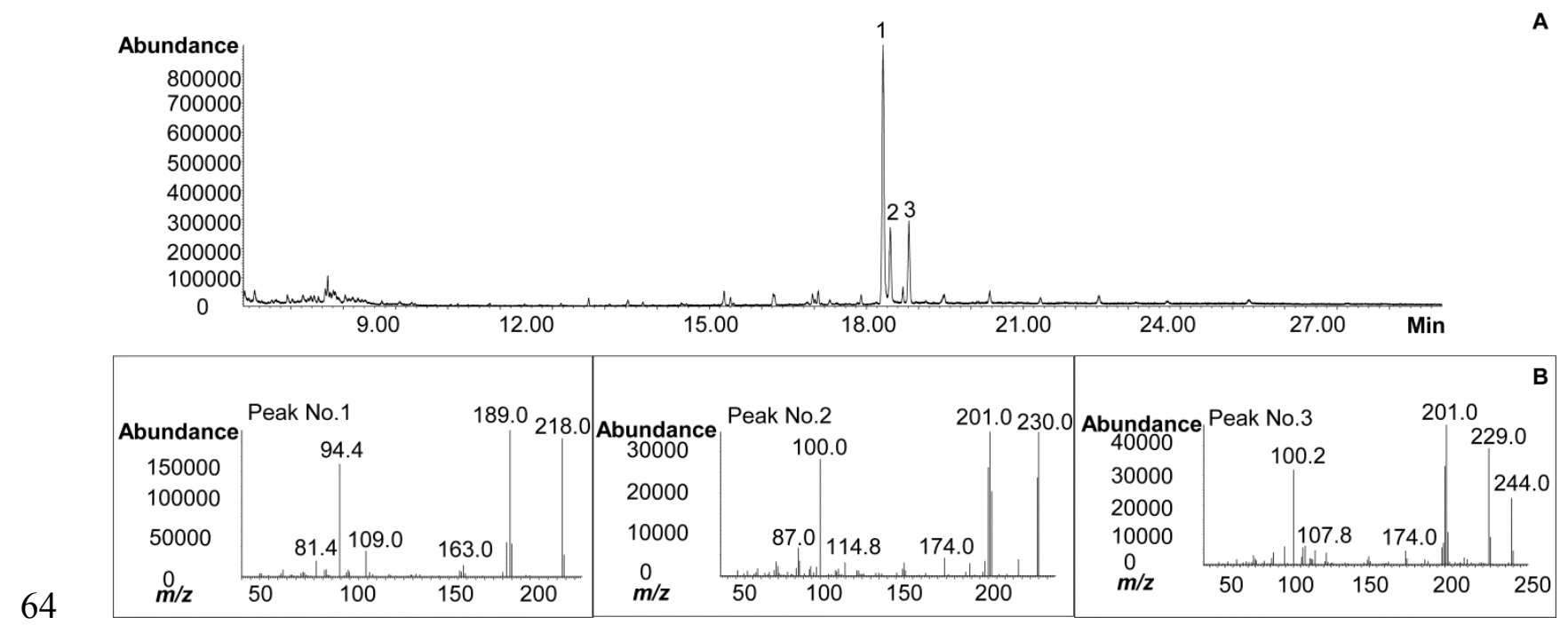

65 Figure S10. (A) GC/MS chromatogram of the eluate from the $\mathrm{B}[a] \mathrm{P}$-specific online HPLC fractionation system 66 with (B) full scan mass spectra from each system peak.

67

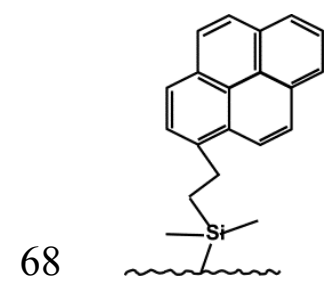

69 Figure S11. Stationary phase structure of the PYE column [1]. 
71 Cell culture and exposure Human hepatocellular carcinoma cells (HepG2) were obtained from the American Type 72 Culture Collection (Rockville, MD, USA) and cultured as described previously [2]. For cell viability experiments, 73 cells were seeded at $5 \times 10^{4}$ cells $/ \mathrm{mL}$ in 24-well plates whereas for Western blot experiments, cells were seeded at 2 $74 \times 10^{5}$ cells $/ \mathrm{mL}$ in 6 -well plates. Cells were cultured for 72 hours, then subsequently exposed to solvent control 75 (0.1\% DMSO), positive control $(3 \mu \mathrm{M} \mathrm{B}[a] \mathrm{P})$, or eluates from the HPLC system for 24 hours. Eluates collected 76 from the $\mathrm{B}[a] \mathrm{P}$-specific online HPLC fractionation system were evaporated and re-dissolved in DMSO for the tests.

77 The same amount of neat hexane was taken and prepared in the same way as method blanks.

78 Cell viability Cell viability was determined by MTT assay as described previously [2]. Briefly, after exposure 79 human HepG2 cells were incubated with $0.5 \mathrm{mg} / \mathrm{mL}$ MTT for 4 hours, then washed and formazan crystals were 80 solubilised in DMSO. Optical density was measured at a wavelength of $590 \mathrm{~nm}$. Data are expressed as percentage of 81 control.

82 Western blotting Protein levels in cells were determined by Western blotting as described previously [2]. Briefly, 83 cell protein samples were subjected to SDS-PAGE and thereafter blotted onto PVDF membrane (Bio-Rad, Hercules, 84 CA). Protein bands were subsequently probed using antibodies. Cell Signaling Technology (Beverly, MA, USA) 85 provided the following antibodies: Chk1 phosphorylated at Ser317 and H2AX phosphorylated at Ser139. Antibodies 86 against Cdk2 (M-2), p53 (DO-1) and secondary anti-rabbit and anti-mouse antibodies were obtained from Santa 87 Cruz Biotechnology (Santa Cruz, CA, USA). Signals were detected using Luminol Western Blotting reagent (Santa 88 Cruz Biotechnology, Santa Cruz, CA, USA). Densitometric analysis was performed using ImageJ software version $891.48 \mathrm{f}$ (National Institute of Health, USA). 

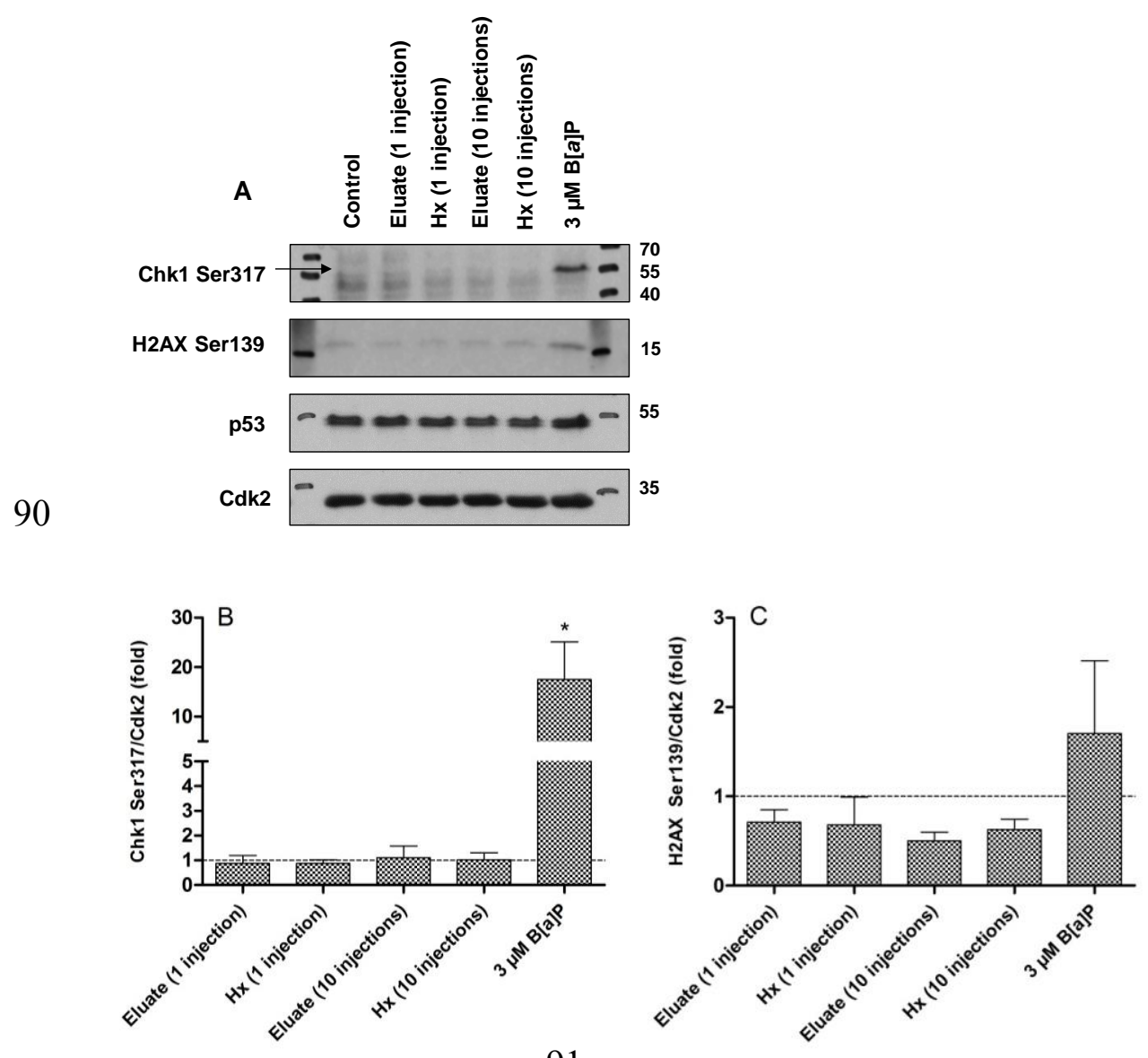

91
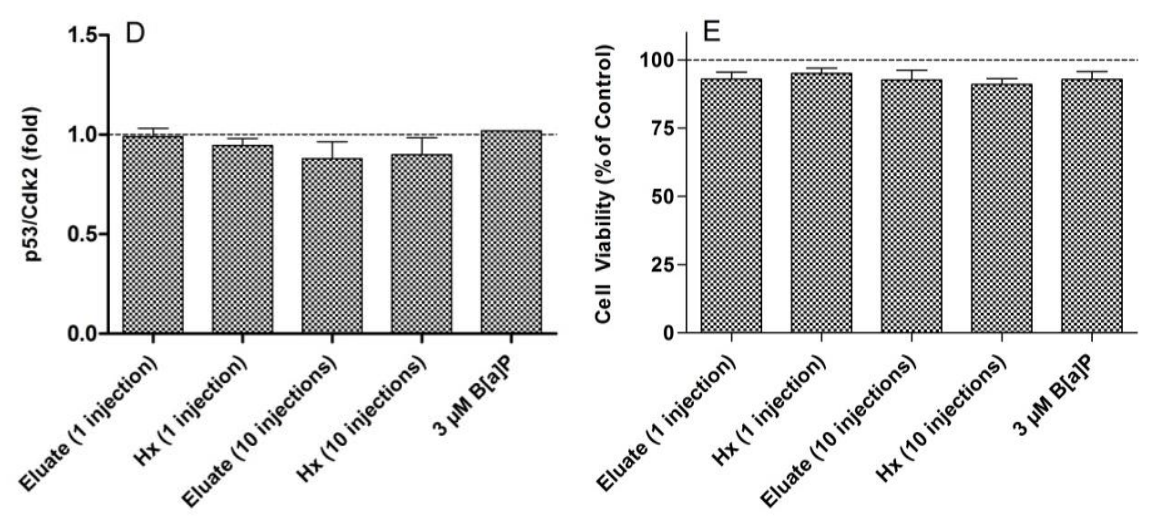

93 Figure S12. Eluates from the $\mathrm{B}[a] \mathrm{P}$-specific online HPLC fractionation system do not induce DNA damage

94 signalling and are not cytotoxic in HepG2 cells. Phosphorylation of Chk1 at Ser317 (A, B) and H2AX at Ser139 (A,

95 C) and levels of p53 protein (A, D) were assessed by Western blotting after 24 hours. Cell viability was assessed by

96 MTT assay after 24 hours (E). Dotted line represents control levels. Experiments were performed in triplicate and

97 data points represent means \pm standard deviations. Where not shown, error lies within the data points. * $\mathrm{p}<0.05$ as

98 compared with control levels by one-way repeated measures ANOVA. 


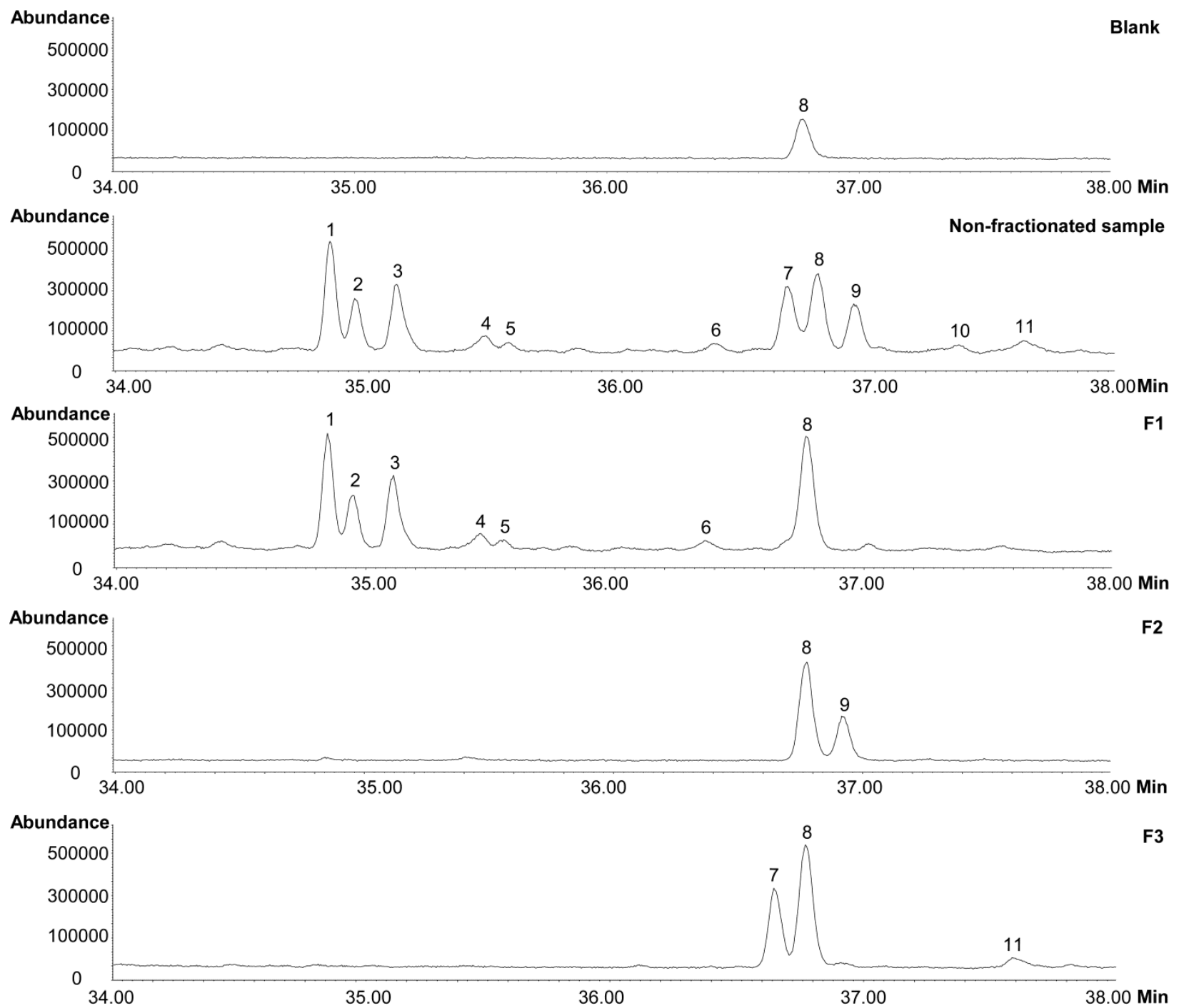

Figure S13. GC/MS chromatograms obtained in full scan mode of blank, non-fractionated and fractionated (F1, F2 103 and F3) samples. 1: B $[b] \mathrm{F}, 2: \mathrm{B}[k] \mathrm{F}, 3: \mathrm{B}[j] \mathrm{F}, 4: \mathrm{B}[a] \mathrm{F}, 5:$ Unknown $(\mathrm{m} / z$ 268), 6: Unknown $(\mathrm{m} / z \mathrm{z} 266), 7: \mathrm{B}[e] \mathrm{P}, 8$ : $104 \mathrm{~B}[a] \mathrm{P}-\mathrm{D}_{12}, 9: \mathrm{B}[a] \mathrm{P}, 10$ : Unknown $(m / z 266), 11$ : Per. Chromatograms were background subtracted and mass data 105 was read from the apex of each peak. 
S-9. PAH concentrations in Stockholm air PM sample

107 Table S4. PAH concentrations $\left(\mathrm{pg} / \mathrm{m}^{3}\right)$ in Stockholm air PM sample. Data obtained in the present study is presented 108 as a mean of three replicates \pm standard deviation.

\begin{tabular}{|c|c|c|c|}
\hline Name & Mean \pm SD $\left(\mathrm{pg} / \mathrm{m}^{3}\right)$ & Name & Mean \pm SD $\left(\mathrm{pg} / \mathrm{m}^{3}\right)$ \\
\hline Phe & $226 \pm 3$ & $\mathrm{~B}[a] \mathrm{A}$ & $304 \pm 5$ \\
\hline Ant & $27.5 \pm 0.5$ & 3-MChr & $27.1 \pm 0.7$ \\
\hline 3-MPhe & $20.2 \pm 0.1$ & 2-MChr & $48.2 \pm 0.8$ \\
\hline 2-MPhe & $29.0 \pm 0.6$ & 6-MChr & $31.7 \pm 0.7$ \\
\hline 2-MAnt & $5.26 \pm 0.05$ & 1-MChr & $51.2 \pm 0.8$ \\
\hline 9-MPhe & $15.3 \pm 0.2$ & $\mathrm{~B}[b] \mathrm{F}$ & $412 \pm 7$ \\
\hline 1-MPhe & $34.5 \pm 0.5$ & $\mathrm{~B}[k] \mathrm{F}$ & $204 \pm 5$ \\
\hline $4 H-\mathrm{CPP}$ & $41.0 \pm 0.1$ & $\mathrm{~B}[e] \mathrm{P}$ & $320 \pm 5$ \\
\hline 2-PN & $26.1 \pm 0.4$ & $\mathrm{~B}[a] \mathrm{P}$ & $297 \pm 8$ \\
\hline 3,6-DMPhe & $1.16 \pm 0.05$ & Per & $47.6 \pm 0.8$ \\
\hline 3,9-DMPhe & $5.94 \pm 0.20$ & $\mathrm{I}[1,2,3-c d] \mathrm{F}$ & $31.7 \pm 0.9$ \\
\hline Flu & $345 \pm 7$ & $\mathrm{I}[1,2,3-c d] \mathrm{P}$ & $230 \pm 4$ \\
\hline Pyr & $390 \pm 8$ & $\mathrm{DB}[a, h] \mathrm{A}$ & $36.7 \pm 0.4$ \\
\hline 1-MFlu & $49.9 \pm 1.1$ & Pic & $38.2 \pm 0.8$ \\
\hline $\mathrm{B}[a] \mathrm{f}$ & $48.8 \pm 0.7$ & $\mathrm{~B}[g h i] \mathrm{p}$ & $352 \pm 8$ \\
\hline $\mathrm{B}[b] \mathrm{f}$ & $29.2 \pm 0.3$ & $\mathrm{DB}[a, l] \mathrm{P}$ & $3.07 \pm 0.17$ \\
\hline 2-MPyr & $24.5 \pm 0.6$ & $\mathrm{DB}[a, e] \mathrm{P}$ & $37.5 \pm 0.8$ \\
\hline 4-MPyr & $34.5 \pm 0.4$ & Cor & $204 \pm 1$ \\
\hline
\end{tabular}




$\begin{array}{lccc}\text { 1-MPyr } & 40.7 \pm 0.3 & \mathrm{DB}[a, i] \mathrm{P} & 11.3 \pm 0.6 \\ \mathrm{~B}[\text { ghi }] \mathrm{F} & 180 \pm 5 & \mathrm{DB}[a, h] \mathrm{P} & 5.54 \pm 0.38 \\ \mathrm{~B}[c] \mathrm{Phe} & 59.8 \pm 2.0 & & \end{array}$

109

111 Reference

112 [1] K. Kimata, K. Hosoya, H. Kuroki, N. Tanaka, J.R. Barr, P.C. McClure, D.G. Patterson Jr., E. Jakobsson, A. 113 Bergman, J. Chromatogr. A 786 (1997) 237.

114 [2] I.W.H. Jarvis, C. Bergvall, M. Bottai, R. Westerholm, U. Stenius, K. Dreij, Toxicol. Appl. Pharmacol. 266 115 (2013) 408. 